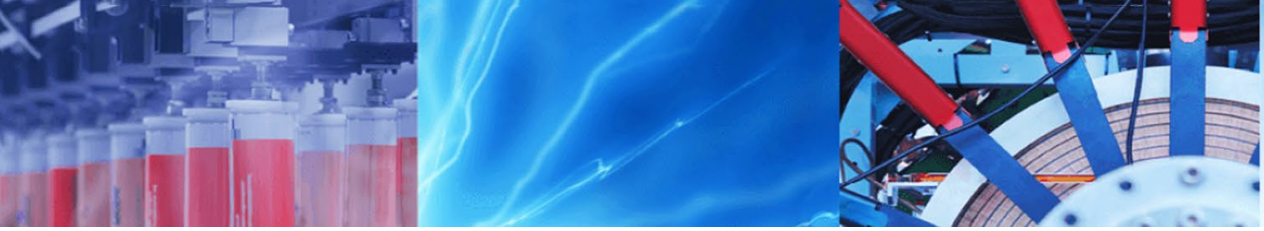

Research Article

\title{
Design of microstrip ultrafast pulses interconnect for THz-analog and digital applications
}

\author{
Y. K. Awasthi ${ }^{1} \cdot$ Himanshu Singh ${ }^{2}$ - A. K. Verma ${ }^{2}$
}

(c) Springer Nature Switzerland AG 2019

\begin{abstract}
In this article, the propagation characteristic of transient pulses over the designed microstrip THz interconnects by various conducting materials is analyzed. The Fourier inverse transformation approach is used to visualize the effect of propagation of transient pulses over $\mathrm{THz}$ interconnects made by the various conducting materials which are widely used in Complementary Metal Oxide Semiconductor (CMOS) technology named Copper, Gold, Aluminum, Tungsten, Tungsten-Silicide ( $\mathrm{W}-\mathrm{Si}_{2}$ ) and Poly-Si respectively. All parameters of transient pulse like rising time, fall time, propagation delay, settling time, overshoot, undershoot and ringing, etc. have calculated using the proposed circuit model and it has been verified with Finite Elements Method based EM-Simulation results. The distortion due to geometrical dispersion is significant; while a loss could be an important factor depending on the dielectric loss of the substrate. This information could be useful in designing both on board and on-chip interconnects. The proposed circuit model of microstrip THz interconnects and algorithmic frameworks proved the usefulness of rapid design, which is extremely challenging when using conventional methods. To the awareness, this is the attempt to efficient solving of this type of design problems; especially in the context of explicit THz interconnect design for CMOS technology.
\end{abstract}

Keywords $\mathrm{THz}$ interconnect · Dispersion · Distortion · Rise-time · Settling time - Ringing · Delay time · Gaussian . Modulated $\cdot$ Exponential signal $\cdot$ Circuit model $\cdot$ Integrated model

\section{Introduction}

The propagation of ultrafast pico-second pulse on the planar transmission line has been extensively studied. Ultra-fast pulses are useful to the modern fast computers, communication, radar, microwave and millimeter wave generation, study of material properties, time-domain network analyzer, Very Large Scale Integration (VLSI) interconnect technology [1-6] etc. Microstrip line is most popular planar line for both analog microwave applications and fast digital applications. The distortion in the electrical pulses traveling on the microstrip line is due to the geometrical dispersion, material dispersion, conductor loss, and dielectric loss. The distortion due to geometrical dispersion is significant; while a loss could be an important factor depending on the dielectric loss of the substrate. The conductor loss role is usually of secondary nature and for good conductor line, its role could not be ignored. The distortion in pulses on the microstrip line due to the geometrical dispersion has been analyzed by using the Finite Element Method (FEM) based HFSS (High-Frequency Structure Simulator) EM-simulator, spectral domain analysis and closed-form model [7].

The effect of conductor and dielectric loss through closed-form models has been included in amplitude factor and phase-factor. Apart from distortion in the digital pulses, propagating on the microstrip line useful for the Microwave Integrated Circuits/Monolithic Microwave

Y. K. Awasthi, yash_ips79@rediffmail.com; Himanshu Singh, drhimanshusingh172@gmail.com; A. K. Verma, anandvrm48@gmail.com | ${ }^{1}$ FET, Electronics and Communication Engineering, Manav Rachna International Institute of Research and Studies, Faridabad, India. ${ }^{2}$ Microwave Research Laboratory, Department of Electronic Science, South Campus, University of Delhi, New Delhi, India.

SN Applied Sciences (2019) 1:948 | https://doi.org/10.1007/s42452-019-0990-6

Received: 23 February 2019 / Accepted: 26 July 2019 / Published online: 31 July 2019 
Integrated Circuits (MIC/MMIC), distortion in Gaussian pulses has also been investigated. It is also useful to estimate the bandwidth of the microstrip line under various conditions [8-12]. The pulse shaping of the exponential pulse has also been investigated [13].

Pulse distortion on microstrip line Several parameters are used to quantify distortion in a rectangular pulse. Distortion in the rectangular pulse is very important in this study. Therefore, these parameters are given below in order to avoid ambiguity in our time-domain discussion and also describe reasons for the distortion in a rectangular pulse [14-23].

Quantification of distortion in pulse Fig. 1 shows the figures of merit with respect to step response of any linear network. The figures of merits are the parameters used to quantify distortion in a rectangular pulse as follows [24].

Rise-time is related to the $3 \mathrm{~dB}$ frequency $\mathrm{f}_{3 \mathrm{~dB}}$ and knee frequency $f_{\text {knee }}$ as $0.35 / T_{r}$ and $0.5 / T_{r}$ respectively. We note that $f_{\text {knee }}>f_{3 d B}$. The $f_{3 d B}$ bandwidth is defined as the passage of only $50 \%$ of the input power to the output. It is not a useful description of the bandwidth of interconnect. The knee frequency $f_{\text {knee }}$ bandwidth permits passage of most energy in digital pulse below $f_{\text {knee }}$. Thus $0.2 \mathrm{ps}$ rise time requires $250 \mathrm{GHz}$ bandwidth microstrip line in order to avoid distortion due to bandwidth limitation [25-27].

A very short interconnect described by the RC-circuit, there is no ringing and overshoot. The amplitude of the pulse response goes negative and it requires setting time. It is expressed as a percentage of the final value [28].

A distortion-less line provides only the time shifting of the input pulse. A pulse transmitting line requires the output sequence of pulse have almost the same distinct pulse shapes without any so-called inter-symbol interference. It is achieved a short rise-time and short settling-time of the line and the long rise-time and long settling-time results in the smearing of pulses shown in Fig. 2 respectively [29].

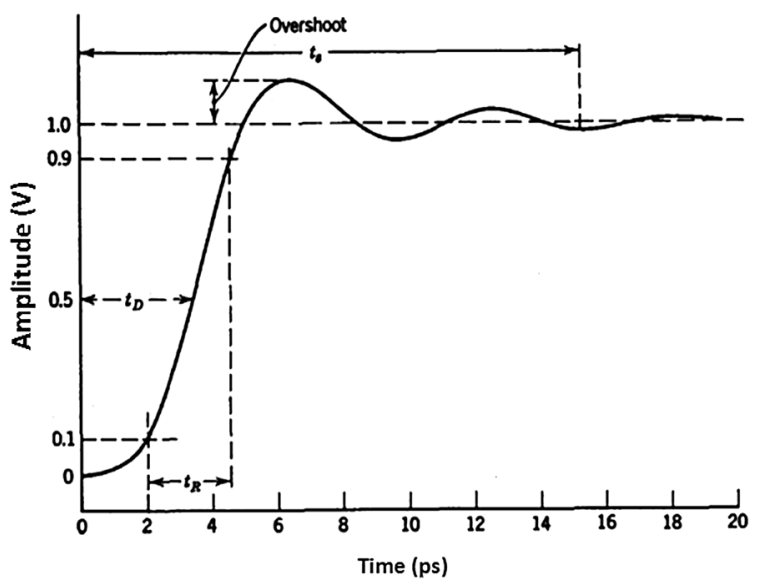

Fig. 1 Figures of merits to quantify distortion in a rectangular pulse

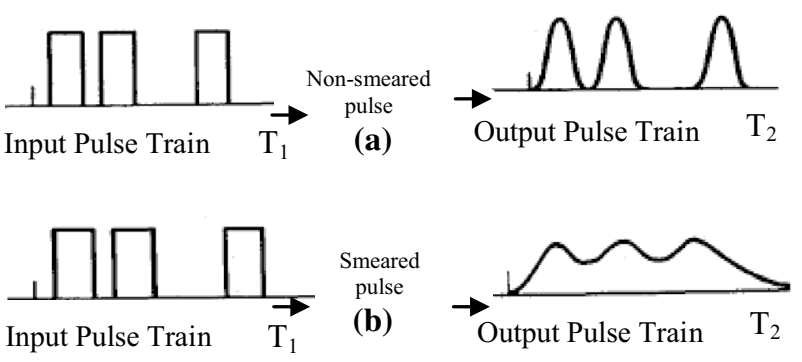

Fig. 2 Non-smeared and smeared pulses due to the rise-time and settling-time

Factors causing distortion in pulse propagation The distortion in pulse propagation on the microstrip line is due to the following factors:

Losses Conductor loss, dielectric loss, and radiation loss, etc. Mode coupling: coupling of higher order modes to the fundamental mode. Dispersion: geometrical dispersion and material dispersion. This article concentrates on pulse distortion due to losses and dispersion in the microstrip line [30-36]. The dispersion in line gives frequency dependent phase velocity of the spectral components of pulse on the line causing distortion in signals. Likewise, the frequency dependent losses also cause distortion in pulses [37]. The dispersion itself causes distortion by four mechanisms: (1) Distortion due to the

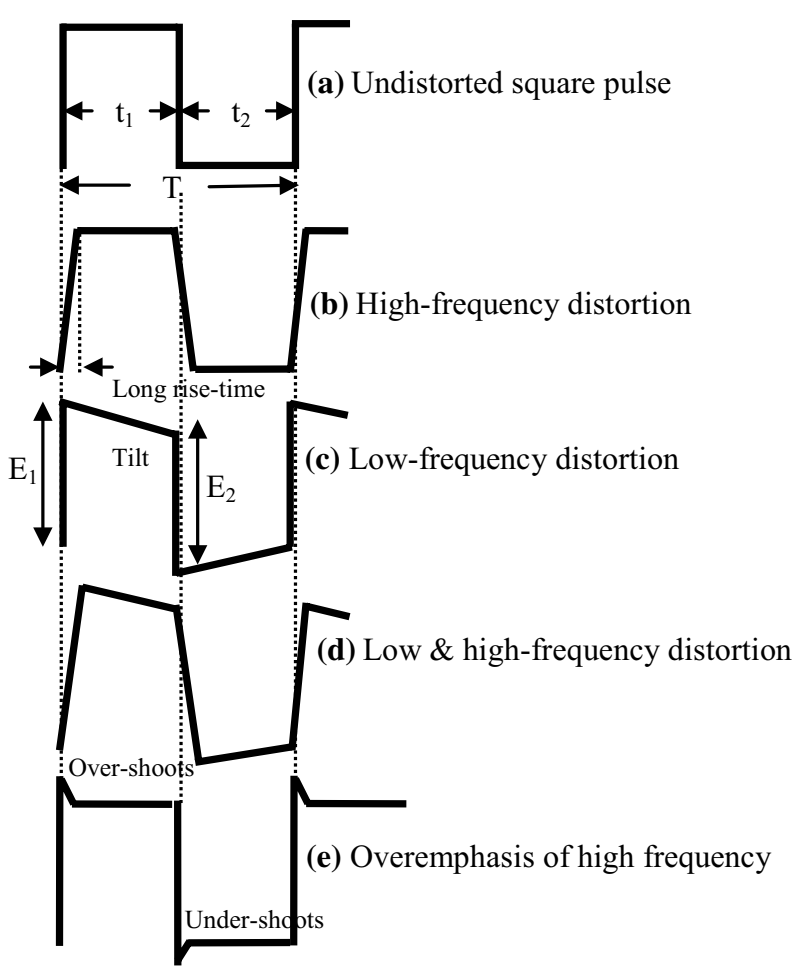

Fig. 3 Nature of distortion in digital pulse

\section{SN Applied Sciences}


Table 1 Input signals and their Fourier transforms, used for analysis

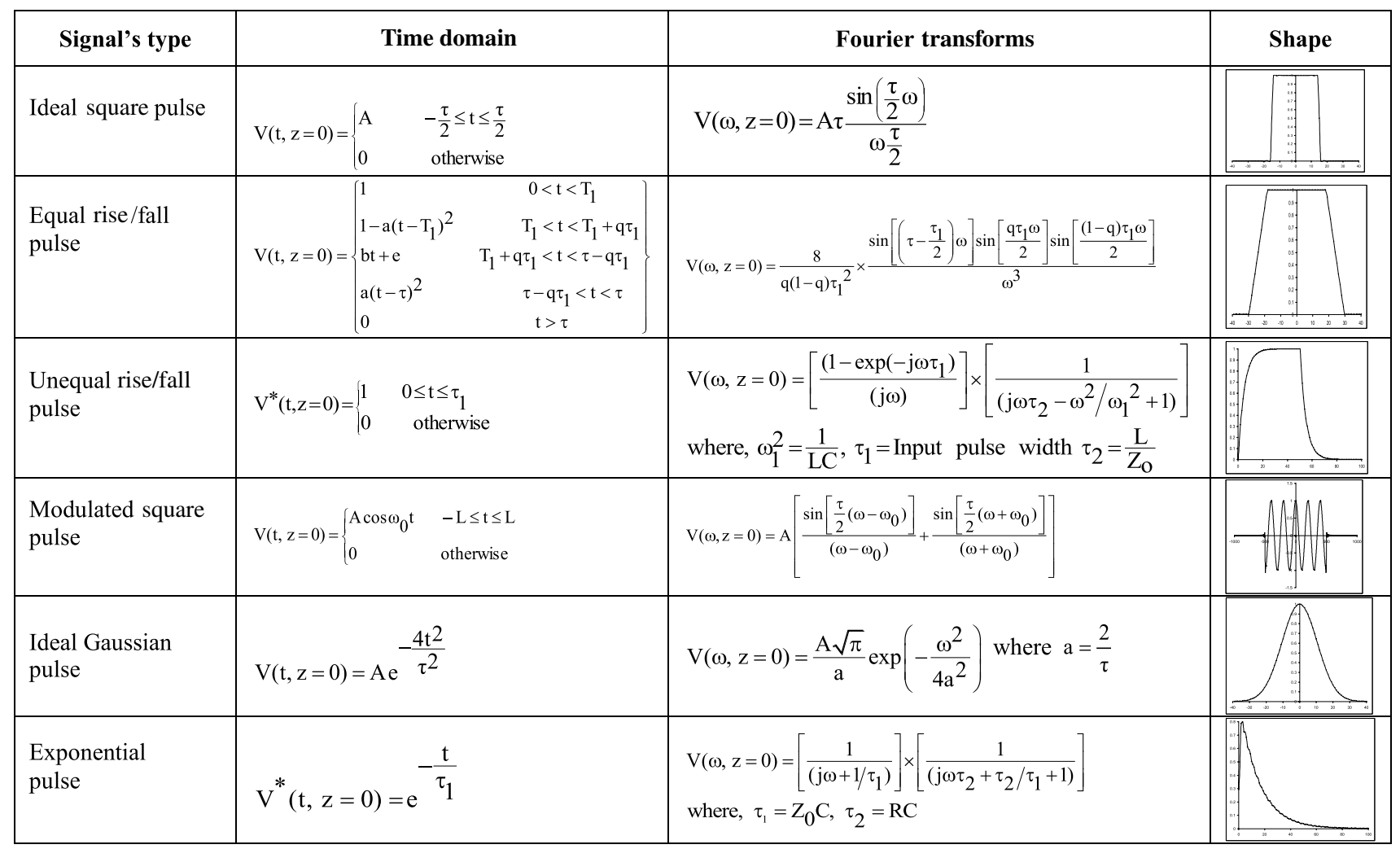

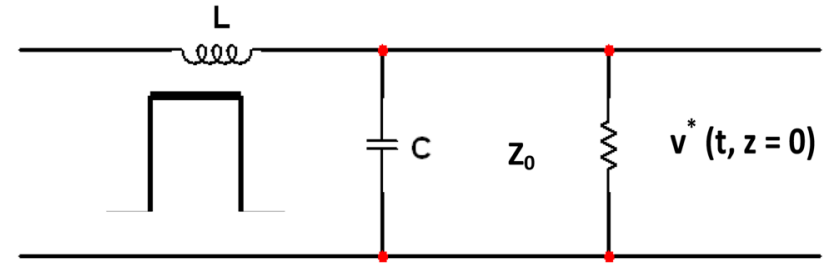

(a)

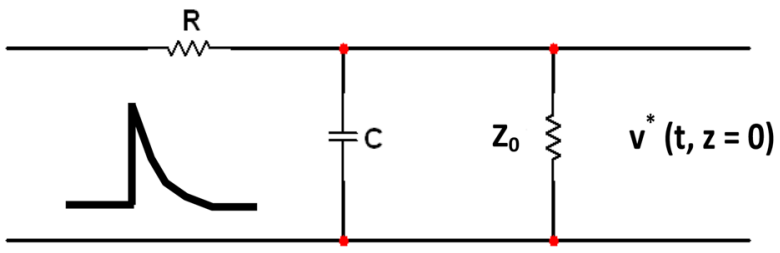

(b)

Fig. 4 Circuit diagrams generating unequal a rise-time and falltime signal rectangular pulse and $\mathbf{b}$ exponential pulse

bandwidth limitation of microstrip transmission line (2) Distortion due to the pulse catching up phenomenon within the pulse-width (3) Distortion due to separation of the low-frequency component of the pulse (4) Distortion due to the separation of the high-frequency pulse.

If a small portion of high-frequency components is separated from the main pulse response of line will look like the response of the low-pass filter. Whereas, if a small portion of low-frequency components is separated from the main pulse, the response of the line will look like a response from high-pass filter [38]. Such distortions in the rectangular pulse are shown in Fig. 3a. Figure $3 \mathrm{~b}$ shows an increase in rise-time i.e. longer rise-time due to the absence of high-frequency spectral components. It is due to the limited bandwidth of a line. Figure $3 c$ shows tilt in the pulse due to the separation of lowfrequency component from the main pulse. Figure $3 d$ shows distortion in the pulse due to the separation of low-frequency components combined with separation of high-frequency spectral components. Figure 3 e shows adding up of high-frequency components during the pulse width time. It is due to delay in the propagation of high-frequency components of the pulse. It results in ringing at the leading and trailing edges of the pulse due to the overemphasis of high-frequency components [39-42].

The dispersion causes broadening of Gaussian pulse i.e. increase in Full width at half maximum (FWHM) at the output of line and spreading of ringing in the time-domain. This is due to the redistribution of spectral energy [43-46]. Such temporal spreading of the pulse increases the separation of the next pulse, thereby decreasing the bit rate of the line. So for the high-speed pulse propagation line 
should be less dispersive. If we concentrate on the main portion of the Gaussian pulse the increase in its pulse width i.e. FWHM is an indication of separation of high-frequency components of the original pulse. The increase in FWHM is a measure of dispersive nature of the line. In the filter theory, such absence of high-frequency components is an indication of band limitation of the filter. Thus the Gaussian pulse-width i.e. FWHM is related to the bandwidth of line [14, 47-52].

In addition, an aerosol-jet printing technique is realized an optical transmitter assembly of a microring modulator and a high-speed CMOS driver in which the bonding wires are replaced by aerosol-jet printed silver interconnects [53]. Furthermore, conventional complementary metal oxide semiconductor (CMOS)-based electronic interconnects are not expected to keep up with the envisioned future board-to-board and chip-to-chip (within multi-chip-modules) interconnect requirements because of bandwidth-density and power-consumption limitations [54]. However, with the CMOS technology shrinking, it becomes critical to delivering high-quality global clock signal with low propagation delay and hence conventional metallic interconnect seems to meet its bottleneck, as a clock distribution network (CDN) might consume up to $50 \%$ of the overall power [55]. So, the Propose formation of ultra-low-cost visible-light integrated optical links by interfacing dense micro-pixellated LED arrays with matching multi-layered multimode polymer waveguide arrays [56].

This paper presents, a detailed study on the effect of various physical parameters of the microstrip transmission line on digital pulses using the circuit model. The accuracy of the circuit model to analyze the pulse shape has been tested against the full-wave analysis \& provides almost identical results in time-domain for various parameters of a lossy microstrip line. We also compare the results of the integrated model, that accounts for the effect of the loss factor only on the amplitude terms of the spectral components and dispersion are accounted for in the phase-factor.
In the case of the low-loss microstrip, both the circuit and integrated models provide almost identical results. However, for highly lossy microstrip their results differ significantly. Thus under such circumstance, the direct model is not adequate and we should use the circuit model for more realistic analysis [7]. Finally, we have investigated the effect of various physical parameters of a microstrip line on the pulse defining parameters- rise time, fall-time, propagation delay, settling time, overshoot and undershoot, etc. This information could be useful for designing both on board and on-chip interconnects. MATLAB programming and Ansoft HFSS simulation tools are used for the entire analysis.

\section{Analysis of signals}

A dispersive and lossy transmission line gives frequency dependent losses and frequency dependent phase velocity to each spectral components of the input time-domain signal. Thus with the help of Fourier transform input time domain signal is decomposed into its spectral components in the frequency domain.

Numerical method to compute response Various voltage $\mathrm{v}(\mathrm{t}, \mathrm{z}=0)$ signals in time-domain used as the input signals to the microstrip line, along with their Fourier transforms are shown in Table 1.

The Fourier transform of the time-domain signal $v(t)$ is obtained from the following expression

$V(\omega, z=0)=\int_{-\infty}^{\infty} v(t, z=0) e^{-j \omega t} d t$

The unequal rise-time and fall-time signal and the exponential signal marked with $\left(^{*}\right)$ in Table 1 are generated through LC and RC circuit shown below in Fig. 4. The Fourier transforms shown in Table 1 for these pulses are for the time-domain signals at the out of the circuits [46].
Fig. 5 a Effect of $\xi(\mathrm{KI})$ on overshoot of 50 ps digital pulse. Complete input pulse with overshoot and undershoot b effect of $\xi(\mathrm{KI})$ on overshoot of 50 ps digital pulse enlarged the view of overshoot

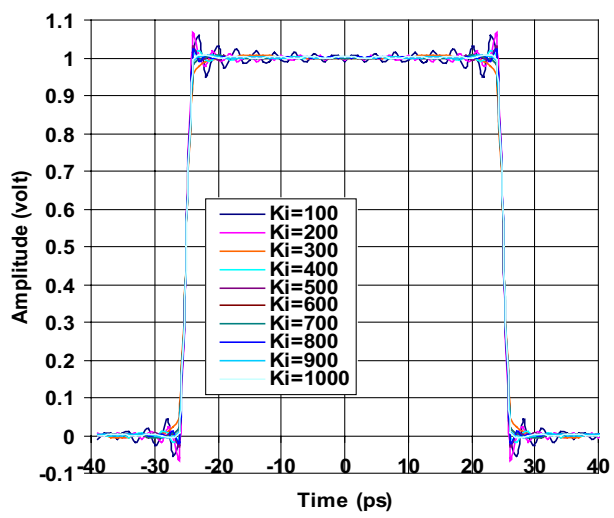

(a)

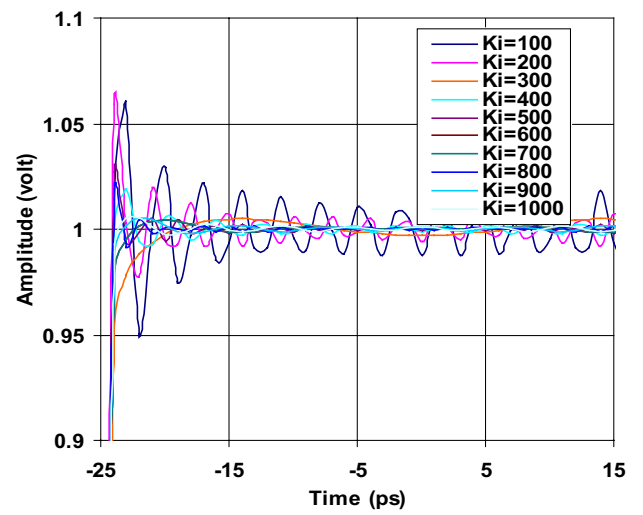

(b) 
Table 2 Effect of $\xi(\mathrm{KI})$ on Overshoot

\begin{tabular}{lllllllllll}
\hline$\xi(\mathrm{KI})$ & 100 & 200 & 300 & 400 & 500 & 600 & 700 & 800 & 900 & 1000 \\
\hline Rise time (ps) & 1.3 & 1.3 & 1.3 & 1.3 & 1.3 & 1.3 & 1.3 & 1.3 & 1.3 & 1.3 \\
Overshoot (\%) & 6.0 & 6.2 & -2.0 & 2.0 & 3.0 & -0.5 & -0.5 & 3.0 & 0.5 & 1.3 \\
\hline
\end{tabular}

Fig. 6 Comparisons of distortion in output pulses as computed by HFSS curve-fitted model and circuit model. For square pulse $\tau=50 \mathrm{ps}$ and for Gaussian pulse $\mathrm{FWHM}=10 \mathrm{ps}$, $\mathrm{w} / \mathrm{h}=0.1$
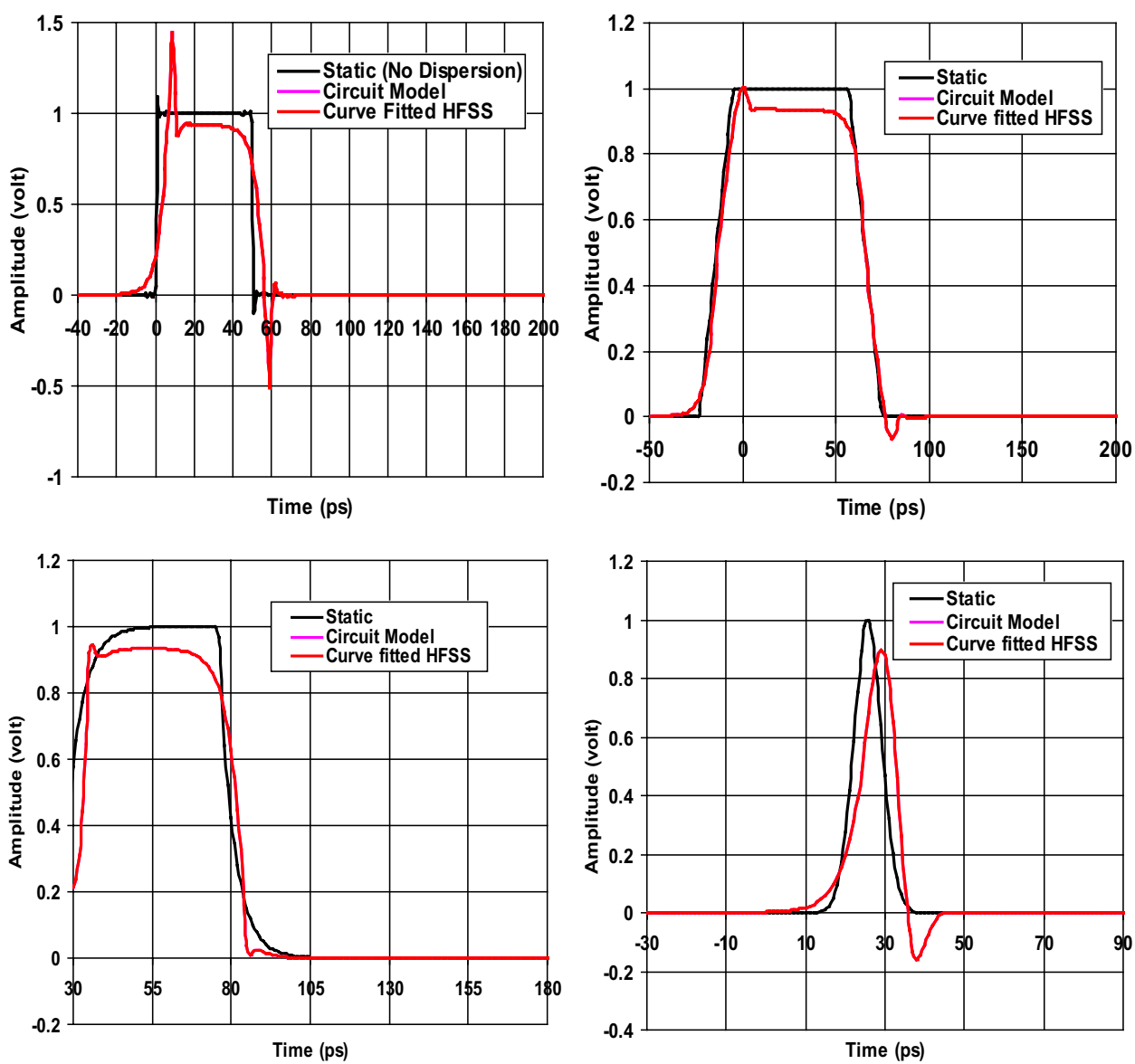

These output signals are fed to the loss microstrip line. The time-constants controlling shape of the pulses is defined in Table 1. The Fourier transform of the pulse provides spectral components. Thus at the end of line length without any reflection the frequency domain response spectral components are given by

$V(\omega, z=L)=H(\omega) \times V(\omega, z=0)$

where $H(\omega)$ is the transfer function of the matched line. For the lossy transmission line, it is given by

$H(\omega)=e^{-\gamma(\omega) L}$

where frequency dependent complex propagation constant $\gamma(\omega)$ is given by

$\gamma(\omega)=\alpha_{T}(\omega)+j \beta(\omega)$

$\beta(\omega)$ is the frequency dependent phase constant of the lossy microstrip line and $\alpha(\omega)$ is the total attenuation factor of the microstrip line due to dielectric and conductor losses. The frequency dependent propagation is obtained from the integrated model using a combination of the MKJ-dispersion model and LDM [7]. It is also determined by the circuit model that accounts for the effect of losses on the propagation constant. Furthermore, it is also determined by the curve-fitted model based on the data obtained from HFSS. This model also accounts for the influence of losses on the propagation constant. The total attenuation factor is

$\alpha_{T}(\omega)=\alpha_{d}(\omega)+\alpha_{c}(\omega)$

where $a_{d}(\omega)$ and $a_{c}(\omega)$ are attenuation factor due to dielectric and conductor losses respectively. The $a_{d}(\omega)$ and $a_{c}(\omega)$ are also obtained from independent closed-form models forming parts of the integrated model. However, the losses are to some extent also influenced by the propagation constants. This is again accounted for by the circuit 
Fig. 7 Comparisons of distortion in output pulses as computed by HFSS curve-fitted model and circuit model. For square pulse $\tau=50 \mathrm{ps}$ and for Gaussian pulse $\mathrm{FWHM}=50 \mathrm{ps}$, $\mathrm{w} / \mathrm{h}=1.0$
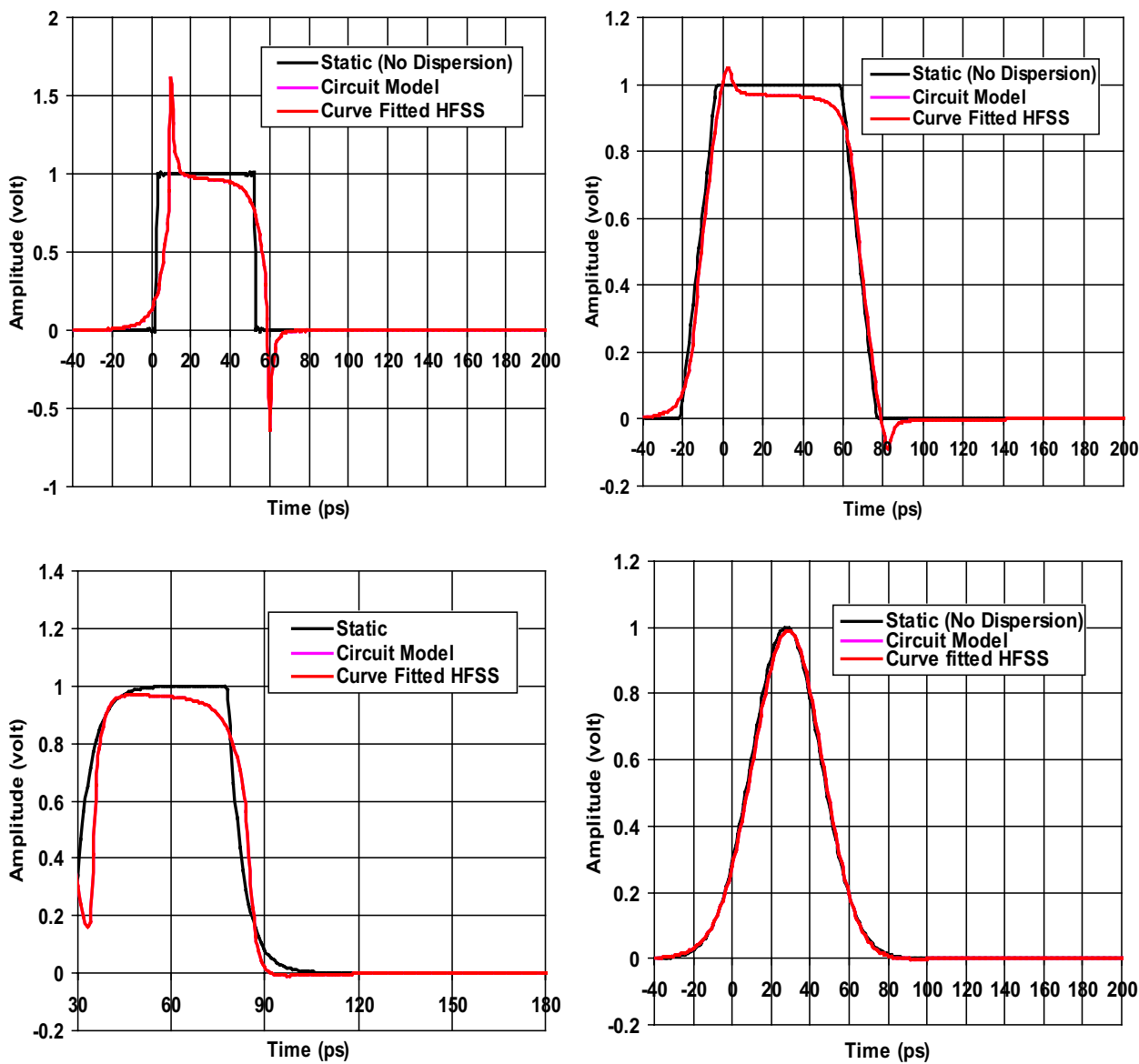

model and the curve-fitted model total attenuation factor $a_{T}(\omega)$ using HFSS data. All these models are discussed in [7]. Finally, the pulse in the time domain at end of the line length $z=L$ is obtained from the inverse Fourier transform

$v(t, z=L)=\frac{1}{2 \pi} \int_{-\infty}^{\infty} H(\omega) \times v(\omega, z=0) e^{j \omega t} d t$

The complexity of the frequency-dependent phase constant $\beta(\omega)$ does not permit solving the Eq. (6) in the closedform. Numerical integration is the most straight forward technique for evaluating Eq. (6). However, its accuracy depends on the amount of computer time and storage space available. Taylor series expansion method could be used for modulated RF pulses. Taylor series expansion method [29] is an approximation to full integration of the Eq. (6). It is slightly less accurate than numerical integration, but it requires much less computer time to evaluate the integral, especially for RF pulses. The FFT process has also been used. In Eq. (6), the limits of integration are $-\infty<\omega<\infty$. However, beyond a certain radian frequency $\omega_{L}$ the contribution of frequency component to the integral are negligible. Narrower pulses have higher frequency content. This leads to a higher value of $\omega_{L}$. If $\tau$ is the width of the pulse, then $\omega_{\mathrm{L}}=\xi / \tau$, Where, $\xi$ is a constant which depends on the wave-shape.

Its value is determined through numerical experimentation. Thus limits of Eq. (7) are restricted to $\pm \omega_{\mathrm{L}}$

$v(t, z=L)=\frac{1}{2 \pi} \int_{-\omega_{L}}^{\omega_{L}} v(\omega, z=0) e^{-\alpha(\omega) L} \cdot e^{j[\omega t-\beta(\omega) L]} d \omega$

The voltage at the output of line is approximated by the trapezoidal rule [16]. For the lossless line, it is given by

$v(t, z=L)=\frac{1}{2 \pi} \sum_{i=1}^{N} v\left(\omega_{i}, z=0\right) \cdot e^{j\left[\omega_{i} t-\beta\left(\omega_{i}\right) L\right]} \Delta \omega_{i}$

For the lossy line voltage at the output is

$v(t, z=L)=\frac{1}{2 \pi} \sum_{i=1}^{N} v\left(\omega_{i}, z=0\right) e^{-\alpha\left(\omega_{i}\right) L} \cdot e^{j\left[\omega_{i} t-\beta\left(\omega_{i}\right) L\right]} \Delta \omega_{i}$ 
Fig. 8 Comparisons of distortion in output pulses as computed by HFSS curve-fitted model and circuit model. For square pulse $\tau=50 \mathrm{ps}$ and for Gaussian pulse $\mathrm{FWHM}=50 \mathrm{p}$, $\mathrm{w} / \mathrm{h}=10$
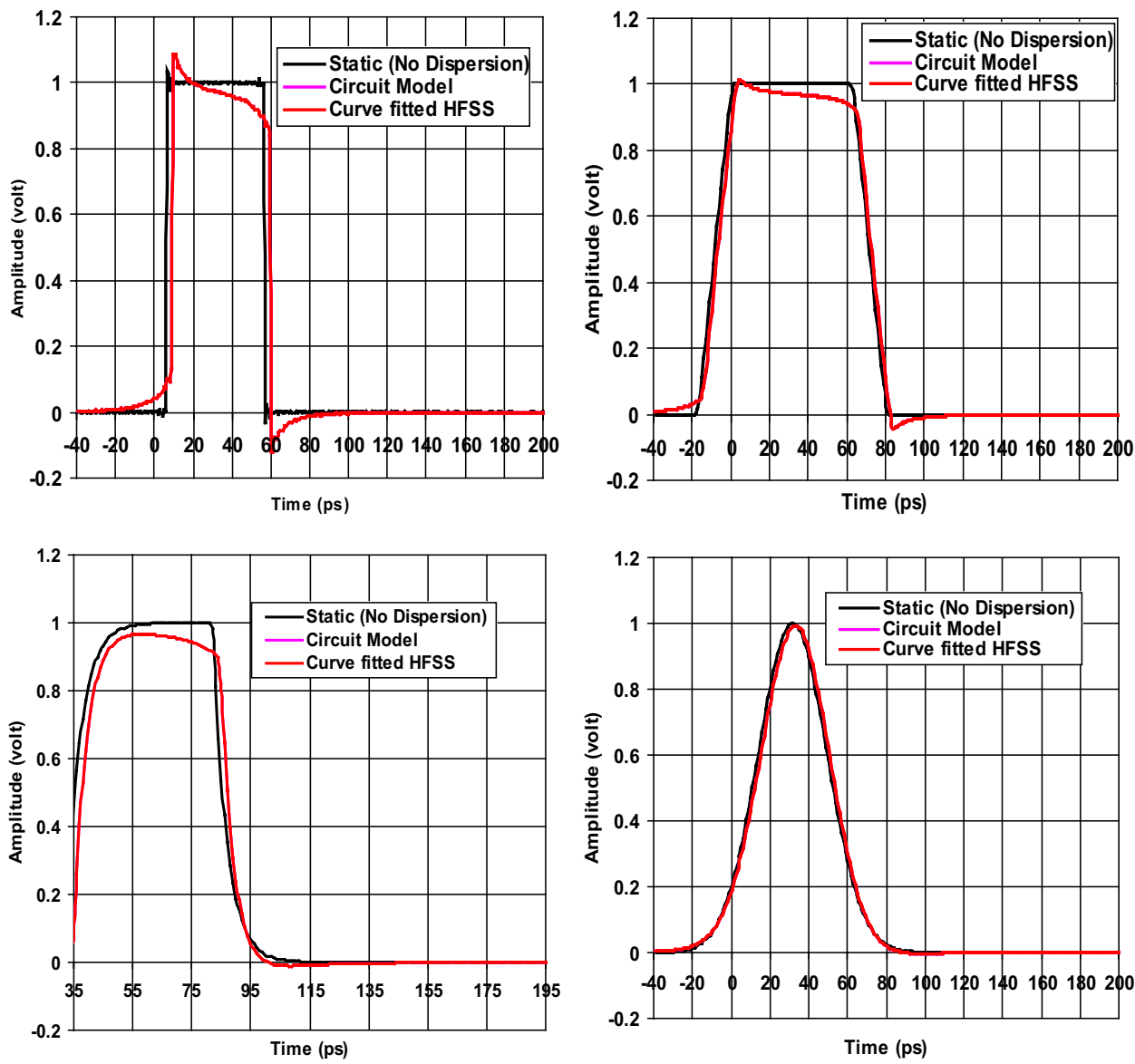

where $\mathrm{N}$ is the number of division in the frequency spectrum and $\Delta \omega=2 \xi / \tau \mathrm{N}$ is the width of each uniform segment. Since we are concerned only with the real part of the pulse, Eq. (9) becomes

$v(t, z=L)=\frac{1}{2 \pi} \sum_{i=1}^{N} v\left(\omega_{i}, z=0\right) e^{-\alpha\left(\omega_{i}\right) L} \cdot \cos \left(\omega_{i} t-\beta\left(\omega_{i}\right) L\right) \Delta \omega_{i}$

For the lossless line, we have $a(\omega)=0$.

Numerical Experimentation to Determine $\xi$ (Kl) for Digital Pulse In above equation $\mathrm{V}\left(\omega_{i}, \mathrm{z}=0\right)$ is the Fourier transform of the digital pulse given in Table 1. In time-domain it is a perfect rectangular pulse. However using Eq. (10), we can regenerate the 50 ps pulse at input, $z=0$. Figure 5 shows such regenerated pulse by changing the value of $\xi$ from 100 to 1000.

Figure 5 a that even the input pulse is no longer a perfect pulse with zero rise-time and with no overshoot and no undershoot. The input $50 \mathrm{ps}$ pulse has rise-time $1.3 \mathrm{ps}$. It requires $385 \mathrm{GHz}$ bandwidth lossless microstrip line to support its undistorted propagation. Figure $5 \mathrm{~b}$ shows enlarged overshoots that are controlled by the value of $\xi(\mathrm{KI})$. The results of experimentation are summarized in Table 2.
The rise-time is not affected by the value of $\xi$. However, \% overshoot is controlled by $\xi$ and its suitable value is $600-700$. For different pulse-width, its value could change. Balanis et al. [30] have suggested its value 500 for the digital pulse and 20 for the Gaussian pulse, as the rise time of a Gaussian pulse is slower.

Separation of frequency components We have mentioned above that the tilt in the response, shown in Fig. $3 c$, is due to the poor low-frequency response of the line. While pulse propagates on the line, its low-frequency spectral component gets separated from the main pulse resulting into the tilt. The separation frequency $f_{L}$ can be estimated as follows:

The phase velocity of pulse at separation frequency $f_{L}$ is related to length $L$ and propagation delay time $\left(t_{d}\right)$ as $V_{p}\left(f_{L}\right)=\left(L / t_{d}\right)$. The delay time $t_{d}$ is the time of arrival of the digital pulse which is measured at $50 \%$ of the amplitude of the pulse. In the above equation, $L$ is known and $t_{d}$ is obtained from the response computed from the above discussed numerical method. Thus, the effective permittivity of microstrip line $K$ at frequency $f_{L}$ is computed from the expression $\mathrm{K}=\left\{\mathrm{V}_{0} /\left(\mathrm{V}_{\mathrm{p}} \times \mathrm{f}_{\mathrm{L}}\right)\right\}^{2}$. Where $\mathrm{V}_{0}$ is the velocity of $E M$-wave in free-space. As $K$ is now known, the separation frequency $f_{L}$ can be obtained by solving the 


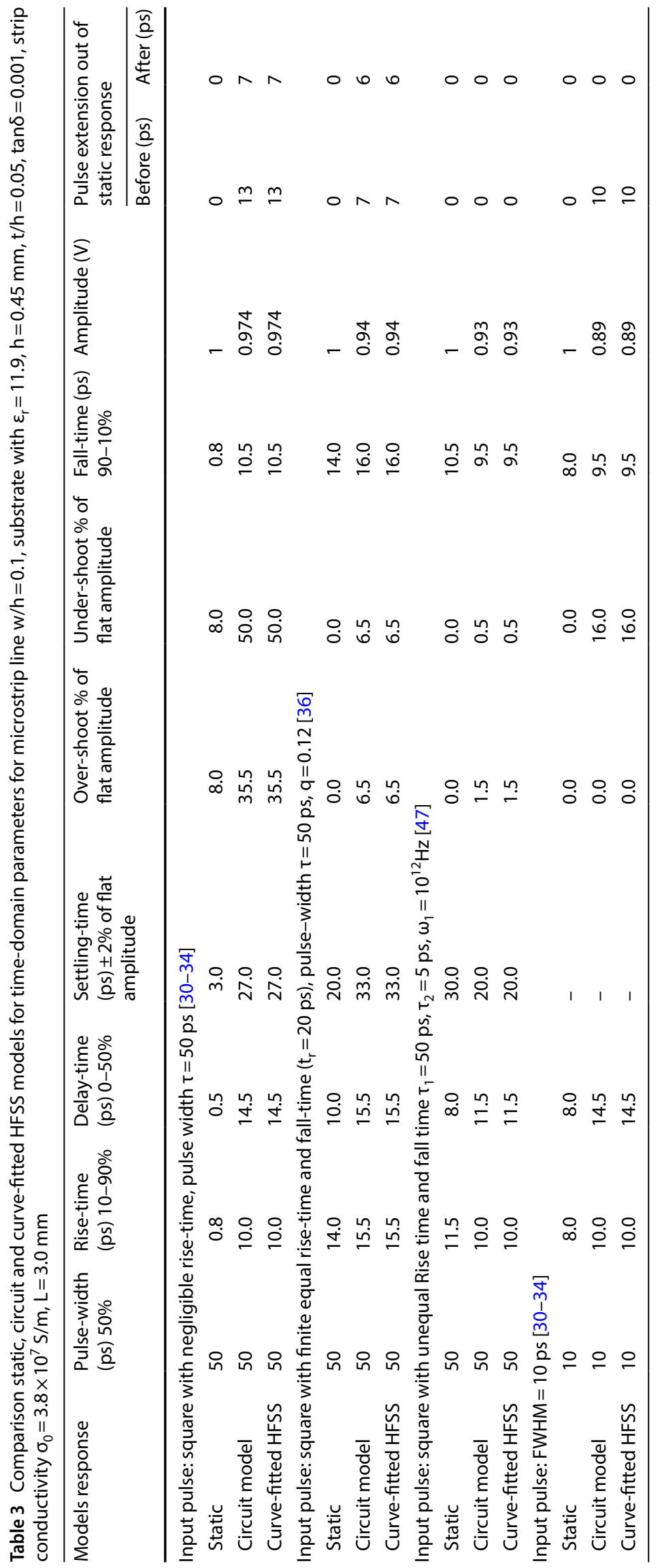




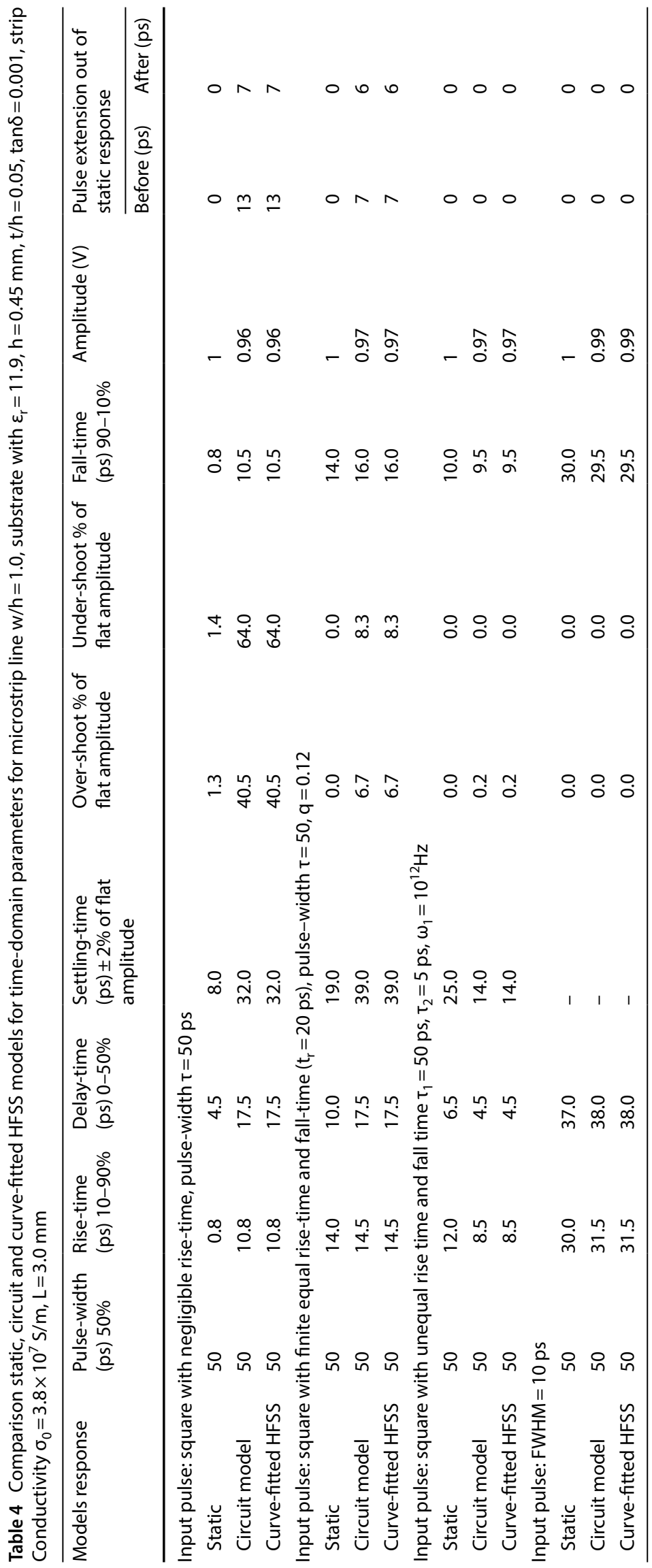




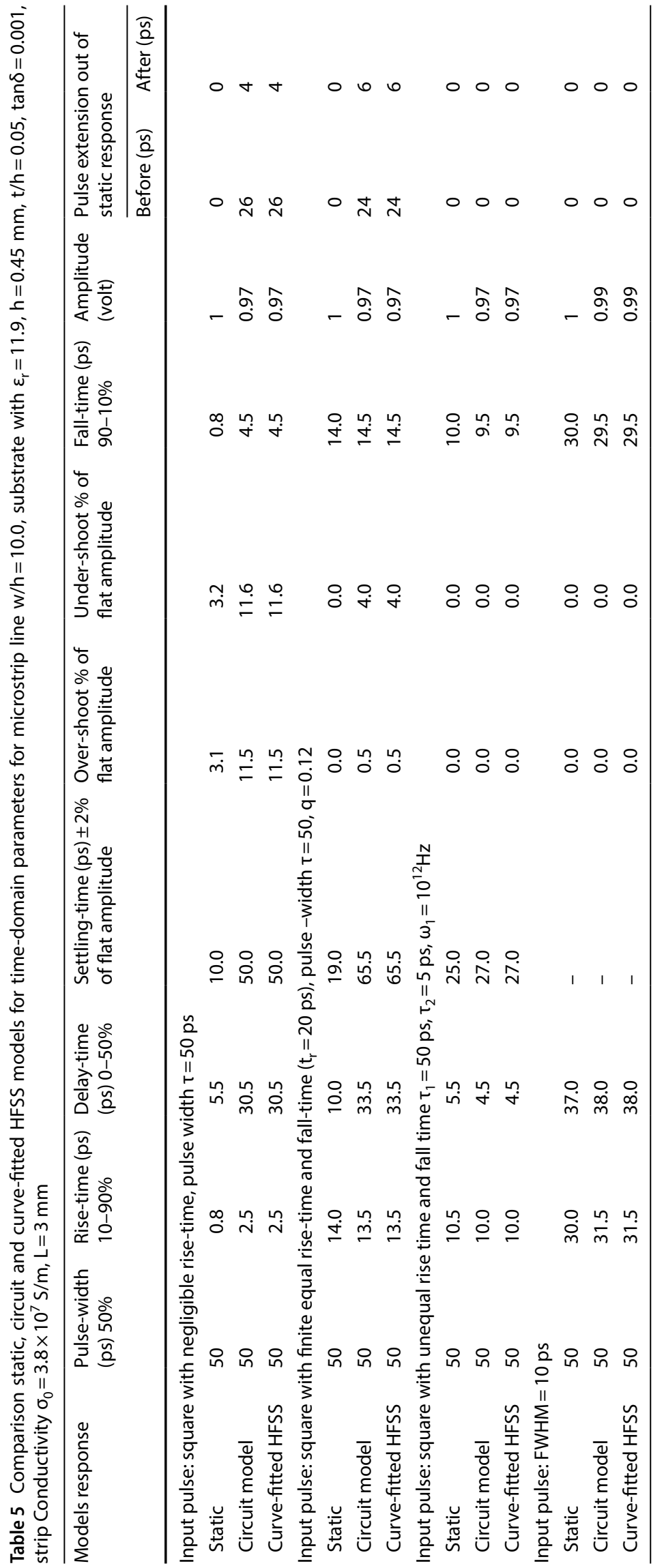


Fig. 9 Distortion in 20 ps Gaussian pulse due to various factor on microstrip line a 5.0 inch b 20.0 inch

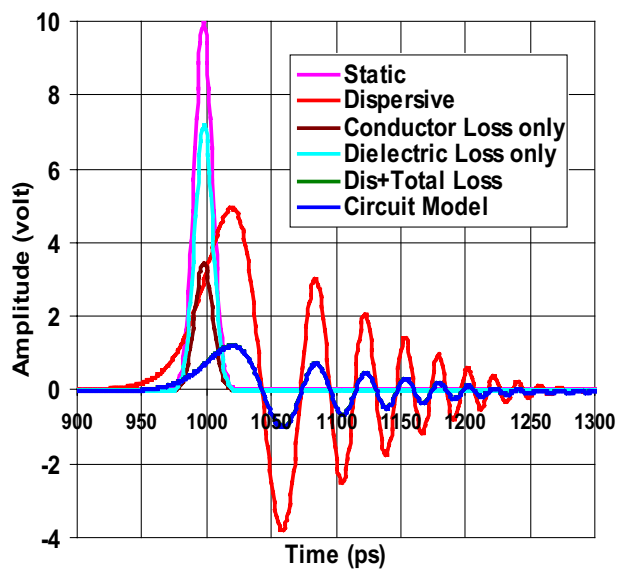

(a)

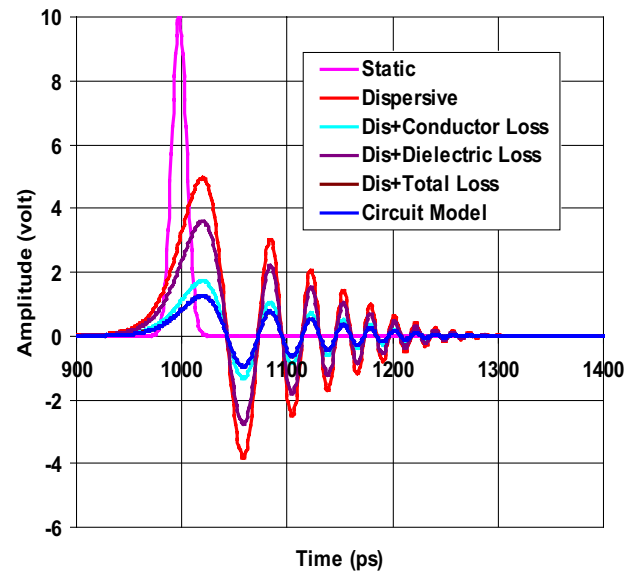

(b)
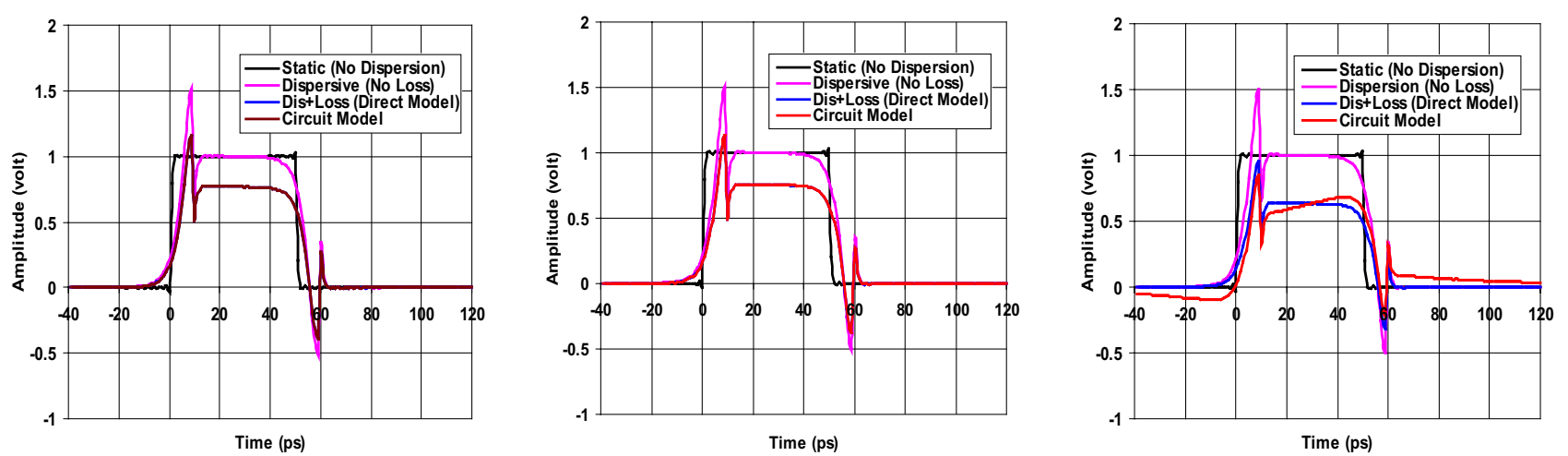

Fig. 1050 ps square-wave on microstrip length $3.0 \mathrm{~mm}$. Strip conductor Tungsten $\left(1.82 \times 10^{7} \mathrm{~S} / \mathrm{m}\right)$, resistivity of Si-substrate $\rho_{\mathrm{s}}=\infty, 100$, $10 \Omega \mathrm{cm}, \mathrm{w}=10 \mu \mathrm{m}$
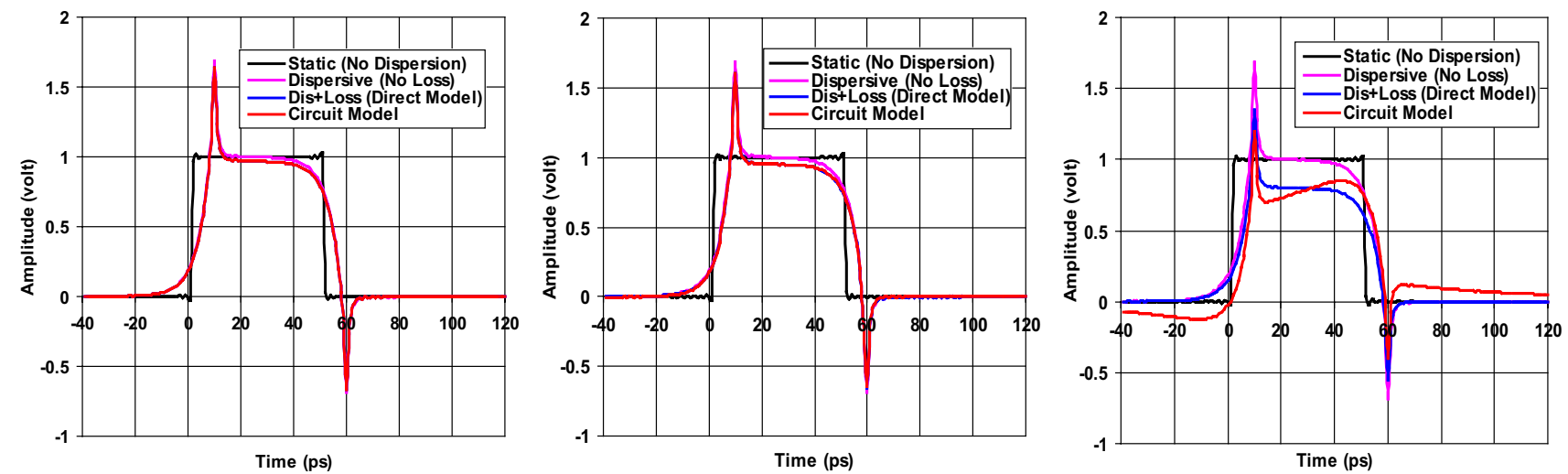

Fig. 1150 ps square-wave on microstrip line length $3.0 \mathrm{~mm}$. Strip conductor tungsten $\left(1.82 \times 10^{7} \mathrm{~S} / \mathrm{m}\right)$, resistivity of Si-substrate $\rho_{\mathrm{s}}=\infty, 100$, $10 \Omega \mathrm{cm}, \mathrm{w}=300 \mu \mathrm{m}$ 

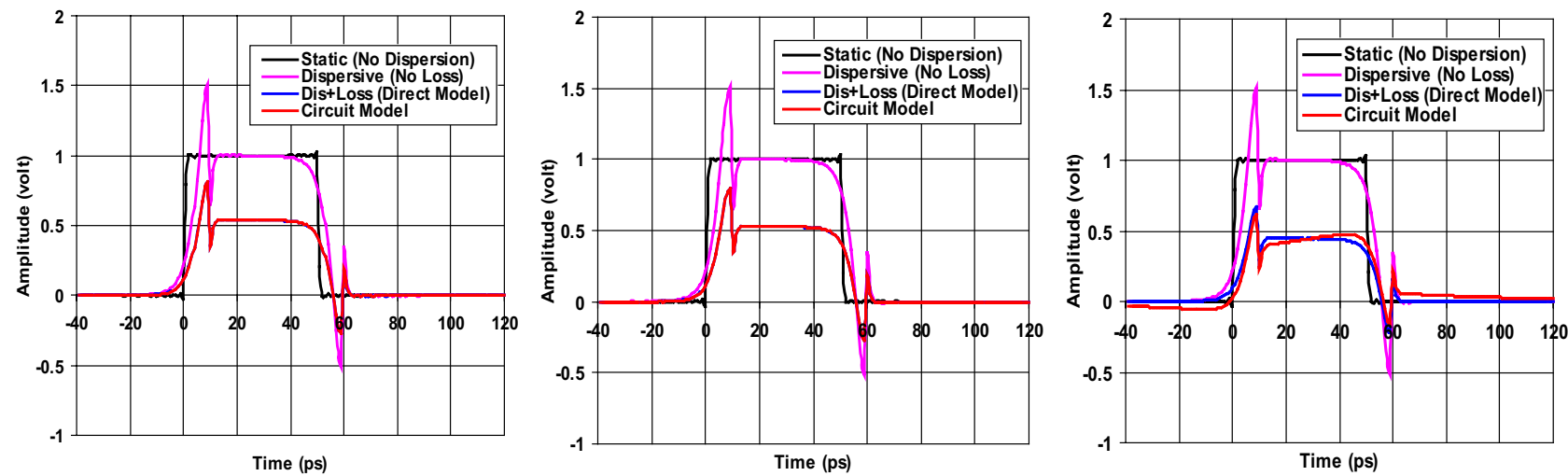

Fig. 1250 ps square-wave on microstrip length $3.0 \mathrm{~mm}$. Strip conductor Tungsten-Silicide $\left(0.33 \times 10^{7} \mathrm{~S} / \mathrm{m}\right)$ resistivity of Si-substrate $\rho_{\mathrm{s}}=\infty$, $100,10 \Omega \mathrm{cm}, \mathrm{w}=10 \mu \mathrm{m}$
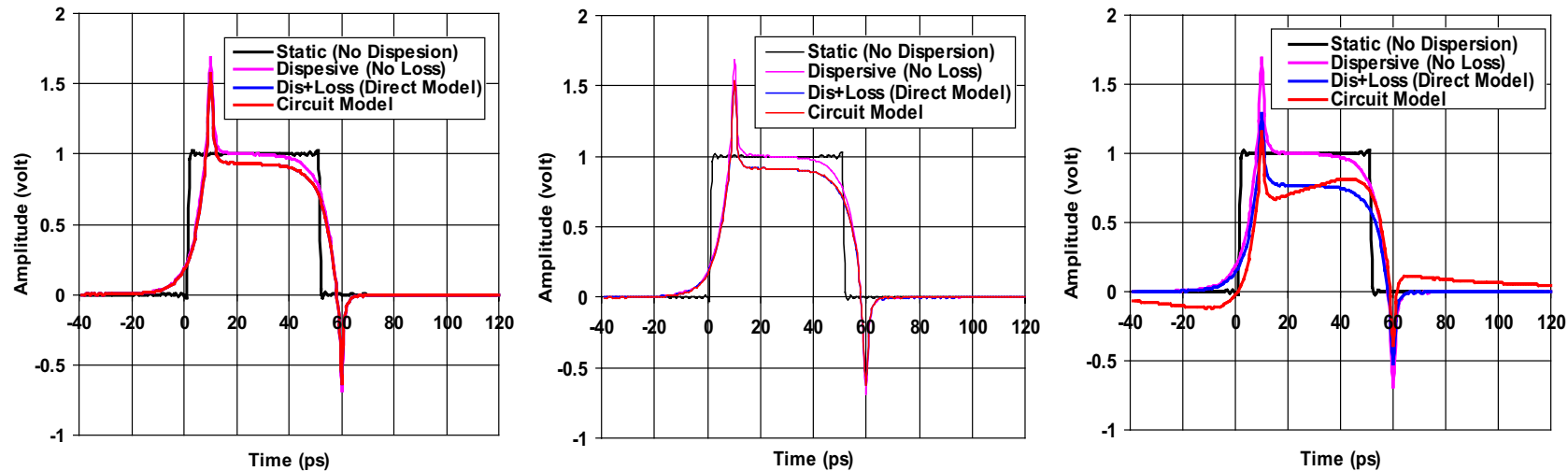

Fig. 1350 ps square-wave on microstrip length $3 \mathrm{~mm}$. Strip conductor tungsten-silicide $\left(0.33 \times 10^{7} \mathrm{~S} / \mathrm{m}\right)$ resistivity of Si-substrate $\rho_{\mathrm{s}}=\infty$, $100,10 \Omega \mathrm{cm}, \mathrm{w}=300 \mu \mathrm{m}$

non-linear equation with the help of the MKJ-dispersion model, $\varepsilon_{\text {reff }}\left(w, h, t, \varepsilon_{r}, f\right)-K=0$ [7]. Finally, the distortion in digital pulse due to the separation of low-frequency components is characterized by the tilt in square digital pulse as defined in Fig. 3c.

Tilt $=\left\{\left(E_{1}-E_{2}\right) / E\right\} \times 100 \%$ where, $E=\left(E_{1}+E_{2}\right) / 2$

The separated high-frequency components are delayed and they combine with low-frequency components of the pulse during pulse width time, thus giving ringing at the leading edge due to the enhancement of high-frequency components. The ringing created due to the numerical process discussed above is known as Gibb's phenomenon.

\section{Numerical results on pulse distortion}

Integrated and circuit models used to compute the attenuation constants and the propagation constant of a lossy microstrip line [7]. The integrated model, also called the direct model as it's every section computes directly from individual expression dispersion, dielectric loss and conductor loss. The circuit model is a more accurate model for high loss microstrip line, as it considers the effect of losses on the propagation constant. We have also reported [7] curve-fitted HFSS models that are based on the data obtained from HFSS. Such curve-fitted models have to be obtained for each individual microstrip line. In this section first, we compare performances of both the curve-fitted 
Fig. 1450 ps square-wave on microstrip length $3 \mathrm{~mm}$. Four types of strip conductor Resistivity of Si-substrate $\rho_{s}=\infty$, $\mathrm{w}=300 \mu \mathrm{m}, \mathrm{t}=0.5 \mu \mathrm{m}$
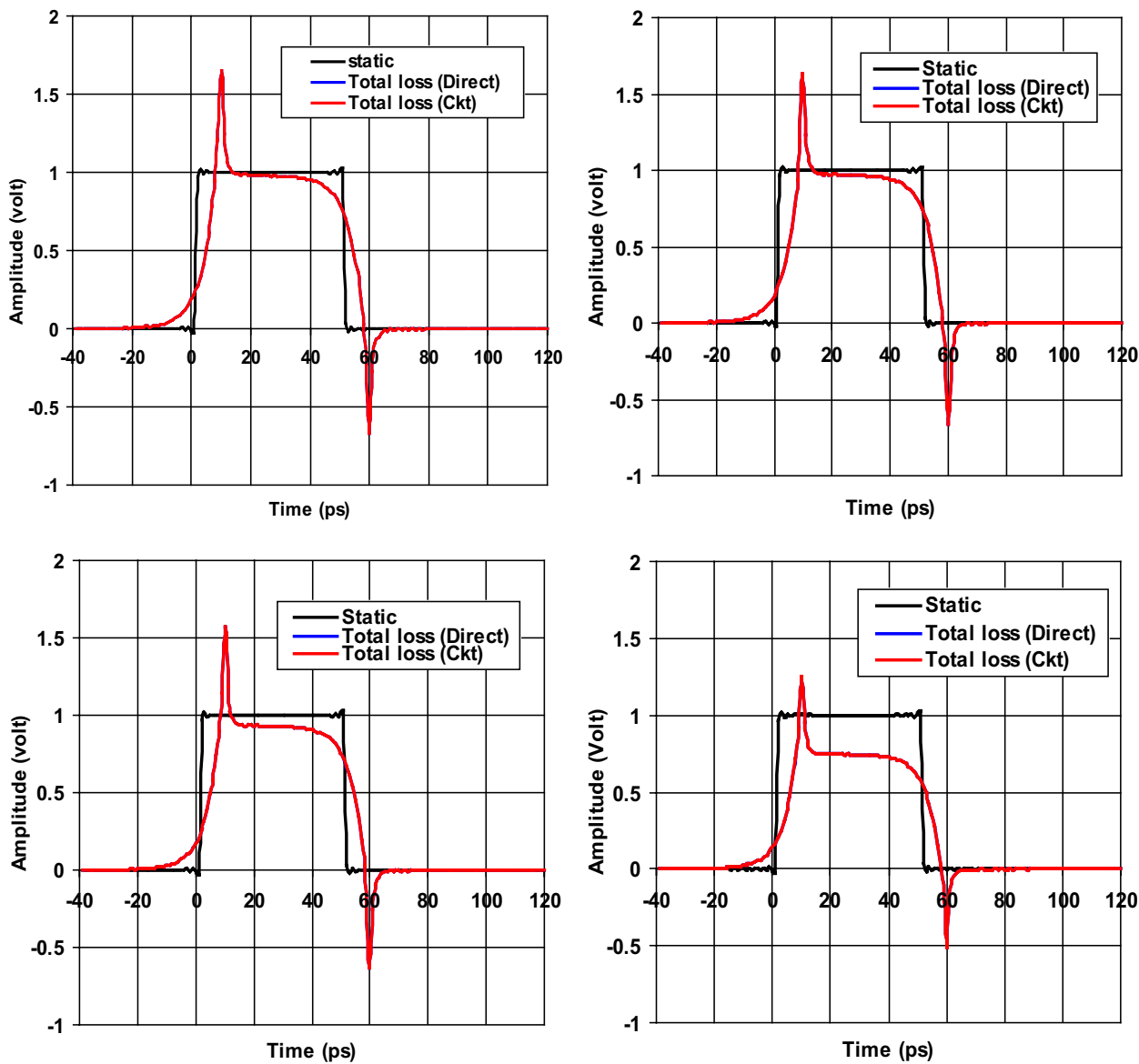

HFSS models and the circuit model in time-domain to obtain the time-domain response of the microstrip line. Next, we compare the performances of the circuit model and the integrated model (direct model) in time-domain. We also present design information for the effect of line width, length, strip conductor conductivity and substrate resistivity on the time-domain direct model parameters, such as rise-time, delay-time, overshoot, etc. of a lossy microstrip.

Performances of Models against HFSS The curve-fitted HFSS models are reported [7], for microstrip line with for various $\mathrm{w} / \mathrm{h}$ as $0.1,1.0,10$. The microstrip is considered on substrate with $\varepsilon_{\mathrm{r}}=11.9, \mathrm{~h}=0.45 \mathrm{~mm}, \tan \delta=0.001$ and strip thickness $\mathrm{t} / \mathrm{h}=0.05$ are aluminum strip conductivity is $\sigma_{0}=3.8 \times 10^{7} \mathrm{~S} / \mathrm{m}$. The curve-fitted HFSS models have a maximum deviation of $1.5 \%$ and an average deviation of $0.8 \%$ for the frequency dependent effective relative permittivity. It has an average deviation of $5.0 \%$ for the total loss computation.
These deviations are against the HFSS data over frequency range $0.01 \mathrm{GHz}-1.0 \mathrm{THz}$. The circuit model has a max deviation of $4.0 \%$ and an average deviation of $2.5 \%$ for dispersion and the average deviation of $8.0 \%$ for total loss against the HFSS data over frequency range $0.01 \mathrm{GHz}-1.0 \mathrm{THz}$. We may state that the circuit model has $1.7 \%$ deviation in the computation of dispersion with respect to the curve-fitted HFSS models and 3.0\% deviation in the computation of total loss respect to the curvefitted HFSS models [7]. We desire to see the effect of these deviations in the circuit models on performances of the pulse distortion with respect to the pulse distortion using curve-fitted HFSS models.

We have considered distortion in four types of input pulses-square pulse with negligible rise-time, finite equal rise-time and fall-time $\left(t_{r}\right)$ square pulse, unequal rise-time and fall-time square pulse and Gaussian pulse. We have considered pulse-width $\tau=50 \mathrm{ps}$ for square pulses and FWHM $=10$ ps for Gaussian pulse. Figures 6, 7 
Fig. 1550 ps square-wave on microstrip length $3 \mathrm{~mm}$. Four types of strip conductor Resistivity of Si-substrate $\rho_{\mathrm{s}}=100 \Omega \mathrm{cm}, \mathrm{w}=300 \mu \mathrm{m}$
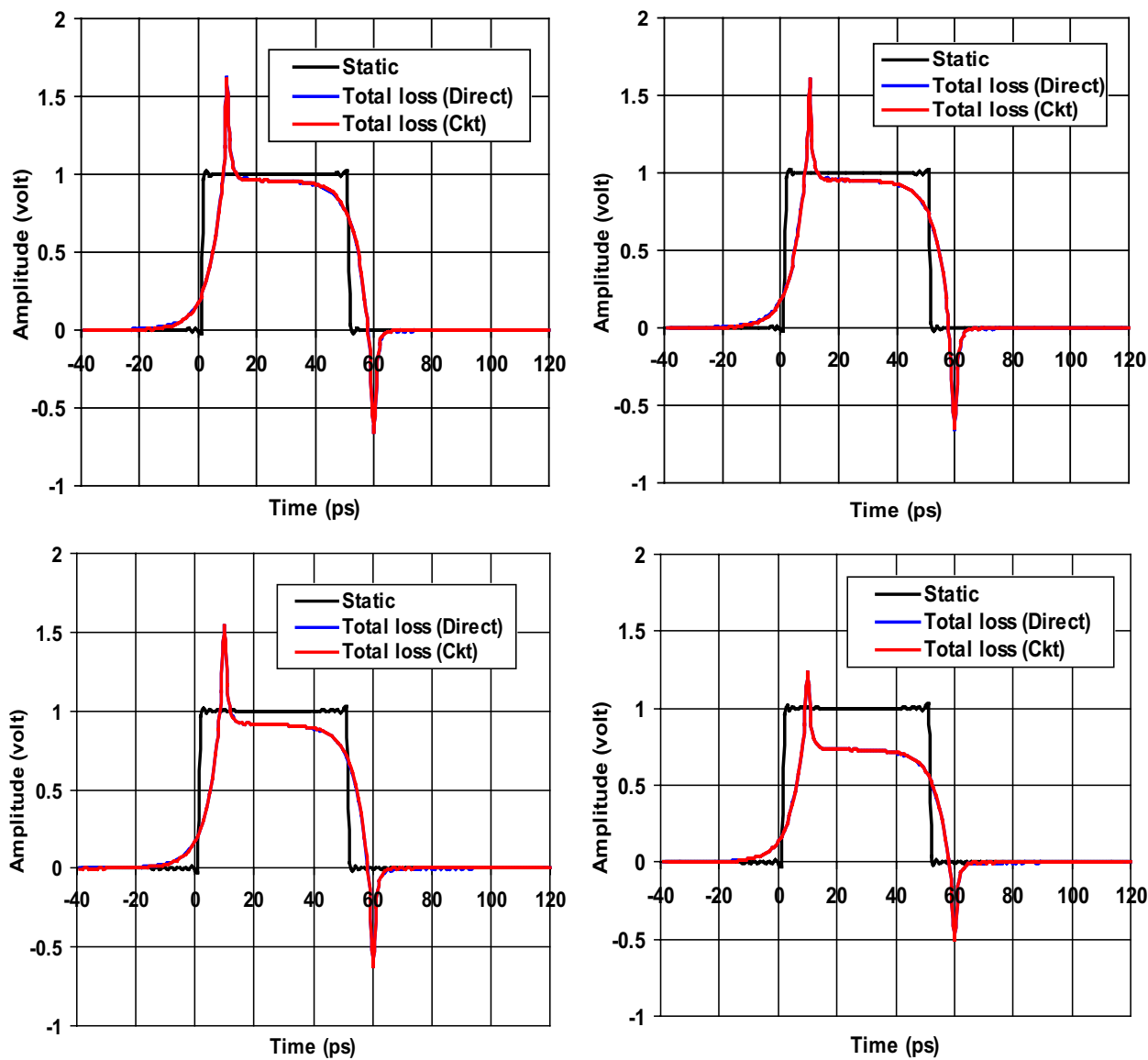

and 8 compares responses of these four input signals on $\mathrm{L}=3 \mathrm{~mm}$ long microstrip of widths $\mathrm{w} / \mathrm{h}=0.1,1.0$ and 10 respectively. Microstrip line are low-loss lines as strip conductor is aluminum $\left(\sigma_{0}=3.8 \times 10^{7} \mathrm{~S} / \mathrm{m}\right)$ and loss-tangent is only 0.001 . Summary of investigation is shown in Tables 3 , 4 and 5 for $w / h=0.1,1.0$ and 10.0 respectively. We note from responses and tables that both the integrated model and circuit modes give identical responses. Thus variations in a deviation between two models ( $1.7 \%$ in propagation constant and 3\% in total loss) do not have an effect on the time domain response of rectangular and Gaussian pulses of $50 \mathrm{ps}$ and $10 \mathrm{ps}$ pulse width.

The extension of response after the end of the response of the static case shows that the pulse response spreads due to dispersion. It limits the speed of data transmission.

If we align the start of the dispersive pulse with the static response to get the physical response, the extension of the pulse due to dispersion will further increase, giving a more realistic picture on inter-symbol interference limiting the bit transmission rate. Our circuit model accuracy with respect to time-domain response and their parameters have been confirmed. Now, we can check the accuracy of the integrated model (direct model) against the circuit model [7].

Comparison of direct model and circuit model In this section, we compare both the direct model i.e. the integrated model and the circuit model with respect to their pulse responses in time-domain. The direct model with changes in dispersion model and some variations in dielectric loss and conductor loss models has been used Balanis et al. [34]. They have not accounted for the effect of the strip conductor thickness in their dispersion models. As mentioned, earlier the direct model does not account for the effect of losses on the propagation constant. It is important for the high loss microstrip. We will examine both models for the lossless, low-loss and high-loss microstrip line.

In the case of the lossless microstrip, both models are identical and only dispersion effect is present. We consider the microstrip line taken by Balanis et al. [32]. This 
Fig. 1650 ps square-wave on microstrip length $3 \mathrm{~mm}$. Four types of strip conductor resistivity of Si-substrate $\rho_{\mathrm{s}}=10 \Omega \mathrm{cm}, \mathrm{w}=300 \mu \mathrm{m}$
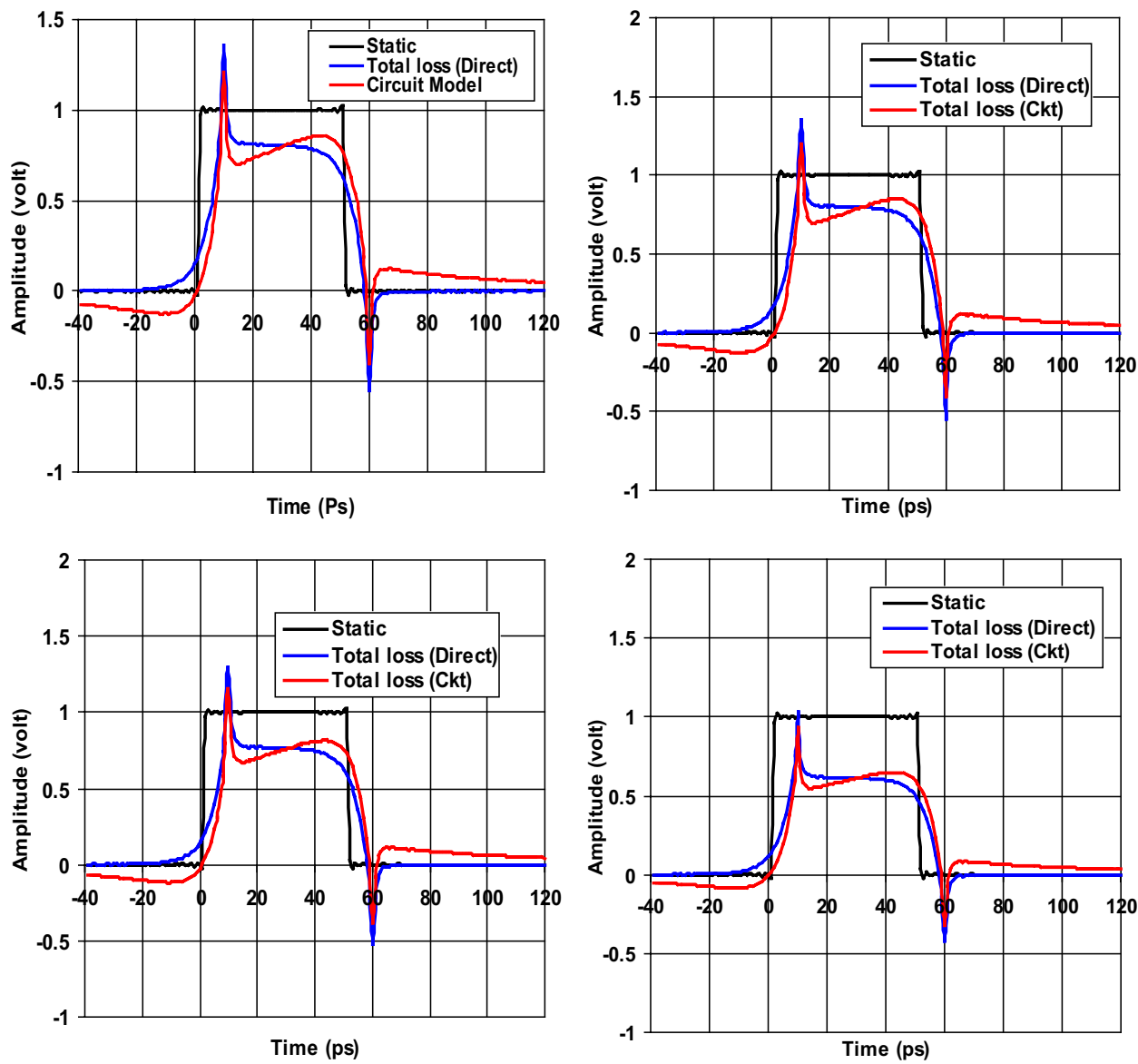

microstrip has substrate with $\varepsilon_{\mathrm{r}}=10.2, \tan \delta=0.0015$, $h=0.02$ inch, $w=0.001$ inch, $t=0.00067$ inch, length $\mathrm{L}=20$ inch, strip is conductor and ground is aluminum.

Another microstrip has length 5.0 inch. The Gaussian pulse has FWHM $=20$ ps. The response of Gaussian pulse for both lines are shown in Fig. $9 a$, b for line length 5.0 inch and 20.0 inch respectively for various conditions- static lossless parameters, dispersion only with no loss, static case with conductor loss, static case with dielectric loss, dispersion and total loss i.e. the direct model and the circuit model.

We note from Fig. 9a that the lossless static case only shifts the pulse in time scale. For the short length line, dielectric loss is less as compared to the conductor loss. It is due to the low-loss substrate. The dispersion is the main reason for spreading of pulse, not losses. Both the direct model and circuit model provide an almost identical response. The models are non-causal and spreading of the pulse is due to dispersion, the losses do not contribute towards it. They only reduce the amplitudes of the main pulse and riggings. This discussion is valid for longer line length shown in Fig. 9b. However, distortion is more. Both models provide identical response only for the low-loss line. It is not true for a high-loss microstrip. It is discussed below.

Figures 10 and 11 show the distortion in $\tau=50$ ps square-wave pulses after $3.0 \mathrm{~mm}$ of propagation on $\mathrm{Si}$ substrate with $\varepsilon_{\mathrm{r}}=11.9, \mathrm{~h}=450 \mu \mathrm{m}$. The strip conductor is made of tungsten $\left(1.82 \times 10^{7} \mathrm{~S} / \mathrm{m}\right)$ and its thickness is $\mathrm{t}=0.5 \mu \mathrm{m}$. The resistivity of the substrate is considered$\rho_{\mathrm{s}}=\infty, 100,10 \Omega \mathrm{cm}$. In Fig. 10 strip width $\mathrm{w}$ is $10 \mu \mathrm{m}$, whereas for Fig. 11 it is $w=300 \mu \mathrm{m}$. Likewise, Figs. 12 and 13 show the distortion in $\tau=50$ ps square-wave pulses after $3.0 \mathrm{~mm}$ propagation on Si-substrate for strip conductor made of tungsten-silicide $\left(0.33 \times 10^{7} \mathrm{~S} / \mathrm{m}\right)$. Other parameters are the same. 
Fig. 1750 ps square-wave on microstrip length $6.0 \mathrm{~mm}$. Strip conductor W-Si $\left(0.33 \times 10^{7} \mathrm{~S} / \mathrm{m}\right)$ Resistivity of Si substrate $\rho_{\mathrm{s}}=\infty, 100,10 \Omega \mathrm{cm}, \mathrm{w}=10 \mu \mathrm{m}$
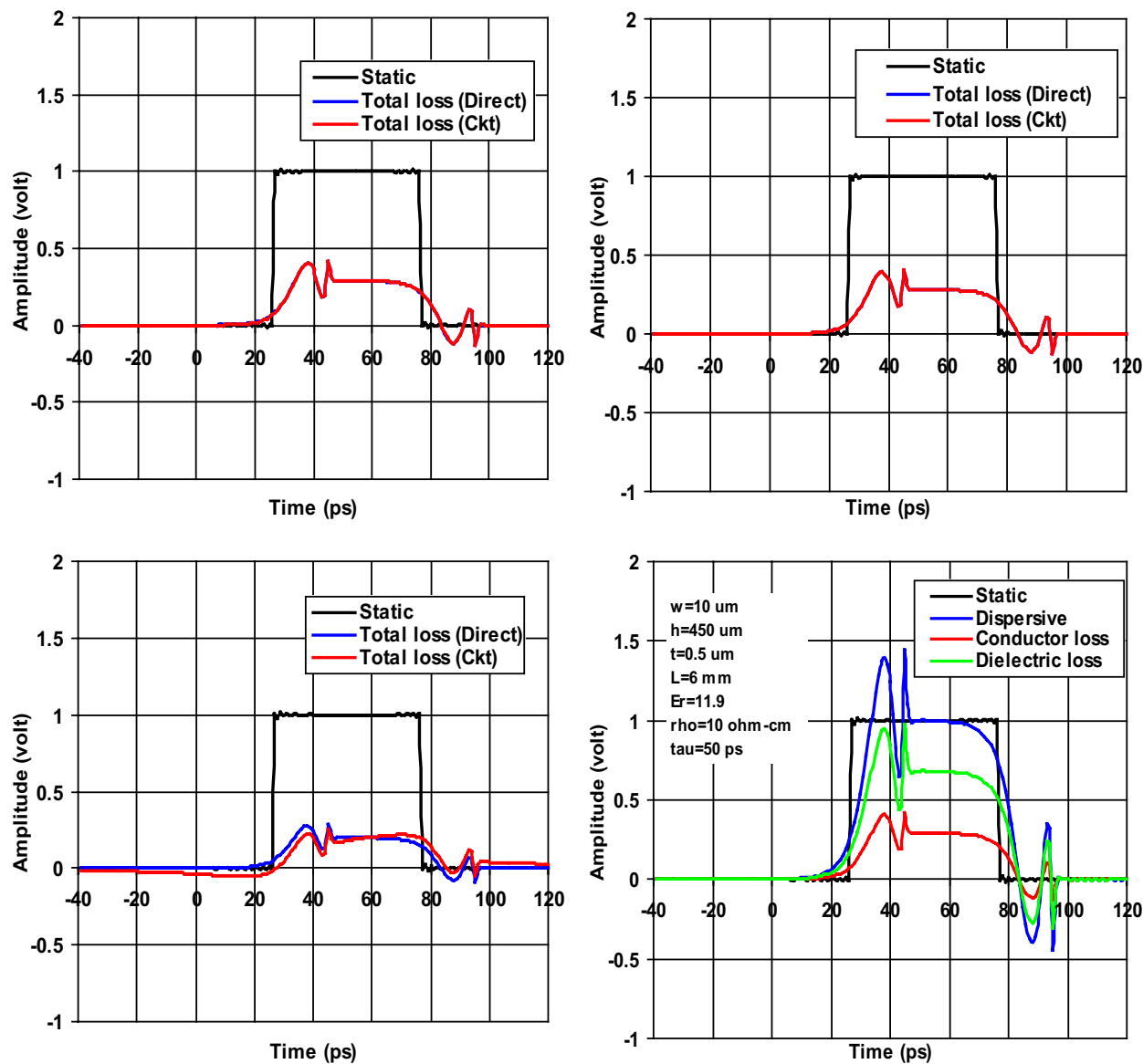

We note that for resistivity of substrate $\rho_{s} \leq 100 \Omega \mathrm{cm}$, both models provide an identical response. However, for resistivity of substrate $\rho_{s}=10 \Omega \mathrm{cm}$, responses of both models are different. Thus we have to use circuit-model for high-loss microstrip line. The effect of various parameters on distortion is discussed in the next section.

We have considered six materials as strip and ground conductors-Copper $\left(5.8 \times 10^{7} \mathrm{~S} / \mathrm{m}\right)$, Gold $\left(4.1 \times 10^{7} \mathrm{~S} / \mathrm{m}\right)$, Aluminum $\left(3.0 \times 10^{7} \mathrm{~S} / \mathrm{m}\right)$, Tungsten $\left(1.82 \times 10^{7} \mathrm{~S} / \mathrm{m}\right)$, Tungsten-Silicide $\left(\mathrm{W}-\mathrm{Si}_{2}\right)\left(0.33 \times 10^{7} \mathrm{~S} / \mathrm{m}\right)$, Poly-Si $\left(0.02 \times 10^{7} \mathrm{~S} / \mathrm{m}\right)$. We have examined several strip width $w=1,10,100,300,450,4500 \mu \mathrm{m}$ and several lengths of microstrip $L=0,3,6,9,12 \mathrm{~mm}$.

Figures 14,15 and 16 show distortion in $\tau=50$ ps. Square-wave pulses after $3.0 \mathrm{~mm}$ of propagation on microstrip with conductors- Aluminum, Tungsten, Tungsten-Silicide $\left(\mathrm{W}-\mathrm{Si}_{2}\right)$, Poly-Si. The pulse width $10 \mathrm{ps}$ and 50 ps have been considered. We have studied distortion in pulses under these parameters. Some of the results are presented in this section. Three figures are for three Si substrates $\left(\varepsilon_{\mathrm{r}}=11.9, \mathrm{~h}=450 \mu \mathrm{m}\right)$ with resistivity $\rho_{\mathrm{s}}=\infty$, $100,10 \Omega \mathrm{cm}$. Microstrip line has $w=300 \mu \mathrm{m}, t=0.5 \mu \mathrm{m}$. We note a gradual increase in attenuation and distortion in pulses with higher dielectric and conductor losses.
Figure 17 further presents distortion and attenuation in 50 ps square-wave on microstrip length having $6.0 \mathrm{~mm}$.

The $10 \mu \mathrm{m}$ wide microstrip is made of conductor $\mathrm{W}-\mathrm{Si}$ $\left(0.33 \times 10^{7} \mathrm{~S} / \mathrm{m}\right)$ on three resistivities of Si-substrate $\rho_{s}=\infty$, $100,10 \Omega \mathrm{cm}$. First three results of Fig. 17 shows gradually increase in attenuation and distortion with a decrease in resistivity of the substrate. The fourth result of Fig. 17 show that distortion is mainly due to dispersion and attenuation in signal is more due to the conductor loss as compared to the dielectric loss even on low-resistivity substrate $\rho_{s}=10 \Omega \mathrm{cm}$. Figure 18 further shows distortion in $\tau=10 \mathrm{ps}$ square pulse dispersion and attenuation with respect to increasing distance for $\mathrm{w} / \mathrm{h}=1.0, \mathrm{~h}=0.45 \mathrm{~mm}$, $\mathrm{t} / \mathrm{h}=0.05, \varepsilon_{\mathrm{r}}=11.9, \tan \delta=0.001, \sigma_{0}=3.8 \times 10^{7} \mathrm{~S} / \mathrm{m}$ and with respect to increasing strip width for $\mathrm{L}=3 \mathrm{~mm}$. The distortion and attenuation significantly increase with an increase in distance. However, the increase in width has a strong influence. The narrow line is more dispersive causing more distortion and also on the low-loss substrate for higher conductor loss. The wide line has less distortion but more loss if the substrate is lossy.

Figure 19 shows variations in the rise-time and delaytime with respect to conductivities of six strip conductors for 50 ps pulse propagating on microstrip with $w=0.3 \mathrm{~mm}$, 


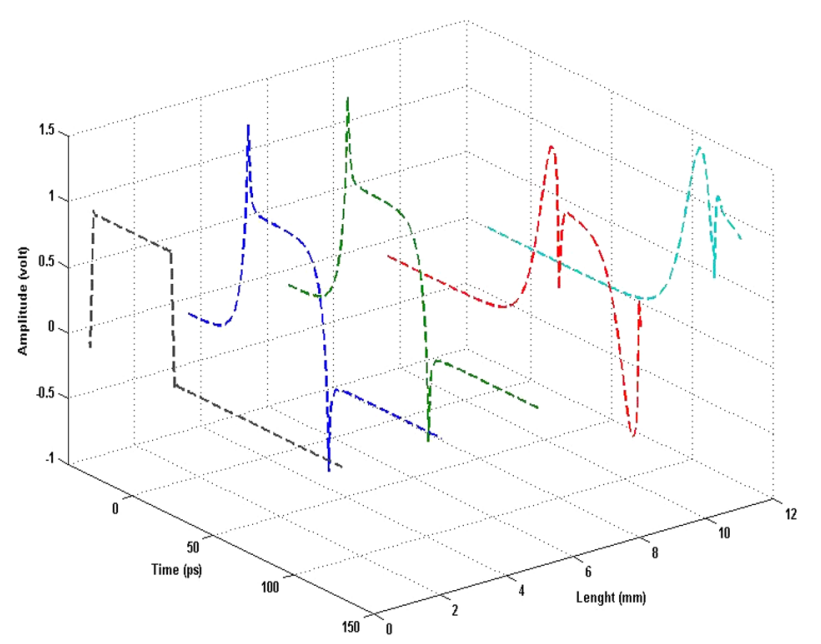

models. The rise-time is not influenced by the conductivity of strip conductor.

Likewise, it is not influenced by the substrate resistivity above $\rho_{s}>100 \Omega \mathrm{cm}$. However, it is influenced by the substrate resistivity below. The rise-time is reduced from 10.5 to 6 ps with a decrease in resistivity from 100 to $10 \Omega \mathrm{cm}$. The delay-time is reduced from 17 to 5.5 ps with a decrease in resistivity from 100 to $10 \Omega \mathrm{cm}$. The low conductivity of the strip conductor has an influence on delay-time. For the high resistivity substrate, $\rho_{s}>10 \Omega \mathrm{cm}$, the delay-time decreases to some extent below conductivity $3 \times 10^{7} \mathrm{~S} / \mathrm{m}$, from 17 to $16 \mathrm{ps}$.

However, for low- resistivity substrate $10 \Omega \mathrm{cm}$, it increases to some extent, from 5.5 to $6.0 \mathrm{ps}$. These results are obtained using the circuit model. Figure 20 shows the effect of strip conductivity on overshoots and undershoots of $50 \mathrm{ps}$ square pulse on microstrip with $\mathrm{w}=0.3 \mathrm{~mm}, \mathrm{~h}=0.45 \mathrm{~mm}, \mathrm{w} / \mathrm{h}=0.67, \boldsymbol{\varepsilon}_{\mathrm{r}}=11.9$, $\mathrm{t}=0.0005 \mathrm{~mm}, \mathrm{~L}=3.0 \mathrm{~mm}$. Results are show for substrate resistivity $\rho_{s}=100 \Omega \mathrm{cm}$ and $\rho_{s}=10 \Omega \mathrm{cm}$. On a high resistivity substrate, both the direct and circuit models provide almost identical results. However, for lowresistivity substrate, $\rho_{\mathrm{s}}=10 \Omega \mathrm{cm}$, results differ significantly. More accurate circuit model shows significantly lower overshoot and undershoot. Low conductivity strip conductors have a lower amplitude of overshoot and undershoot. It is due to high conductor loss. However, we noted above that it also increases attenuation for the main body of the pulse. It is not desirable.

Fig. 18 Distortion in 10 ps pulses with a $L=0,3,6,9,12 \mathrm{~mm}$ for $w / h=1.0$ b $w=1,10,100,300,450,4500 \mu \mathrm{m}$ for $L=3.0 \mathrm{~mm}$

$\mathrm{h}=0.45 \mathrm{~mm}, \mathrm{w} / \mathrm{h}=0.67, \varepsilon_{\mathrm{r}}=11.9, \mathrm{t}=0.0005 \mathrm{~mm}, \mathrm{~L}=3 \mathrm{~mm}$. Three substrate resistivity $\rho_{s}=\infty, 100,10 \Omega \mathrm{cm}$ are considered. Results are shown for both the direct and circuit

\section{Conclusion}

This article has been analyzed the propagation characteristics of transient pulses over the designed THz interconnects. The Fourier transformation approach has been used
Fig. 19 Effect of strip conductivity on a rise-time $\mathbf{b}$ delaytime on 50 ps pulse

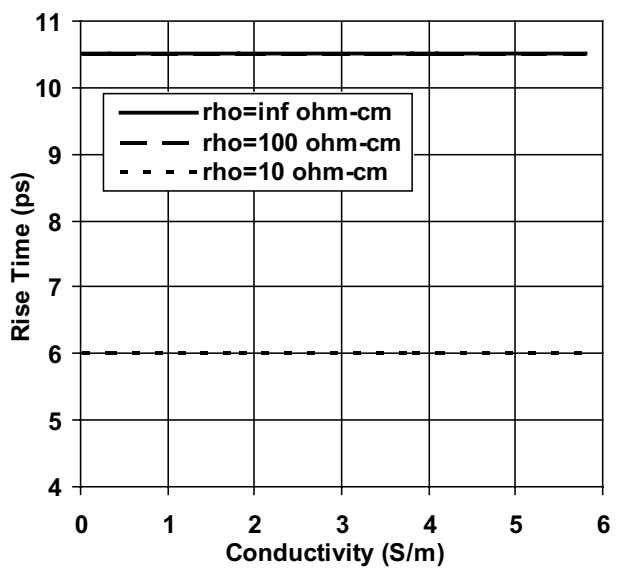

(a)

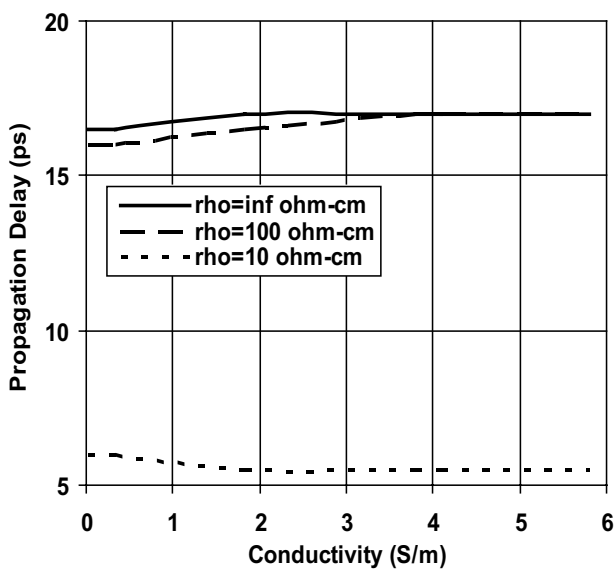

(b) 
Fig. 20 Effect of strip conductor conductivity on undershoot and overshoot of $50 \mathrm{ps}$ pulse
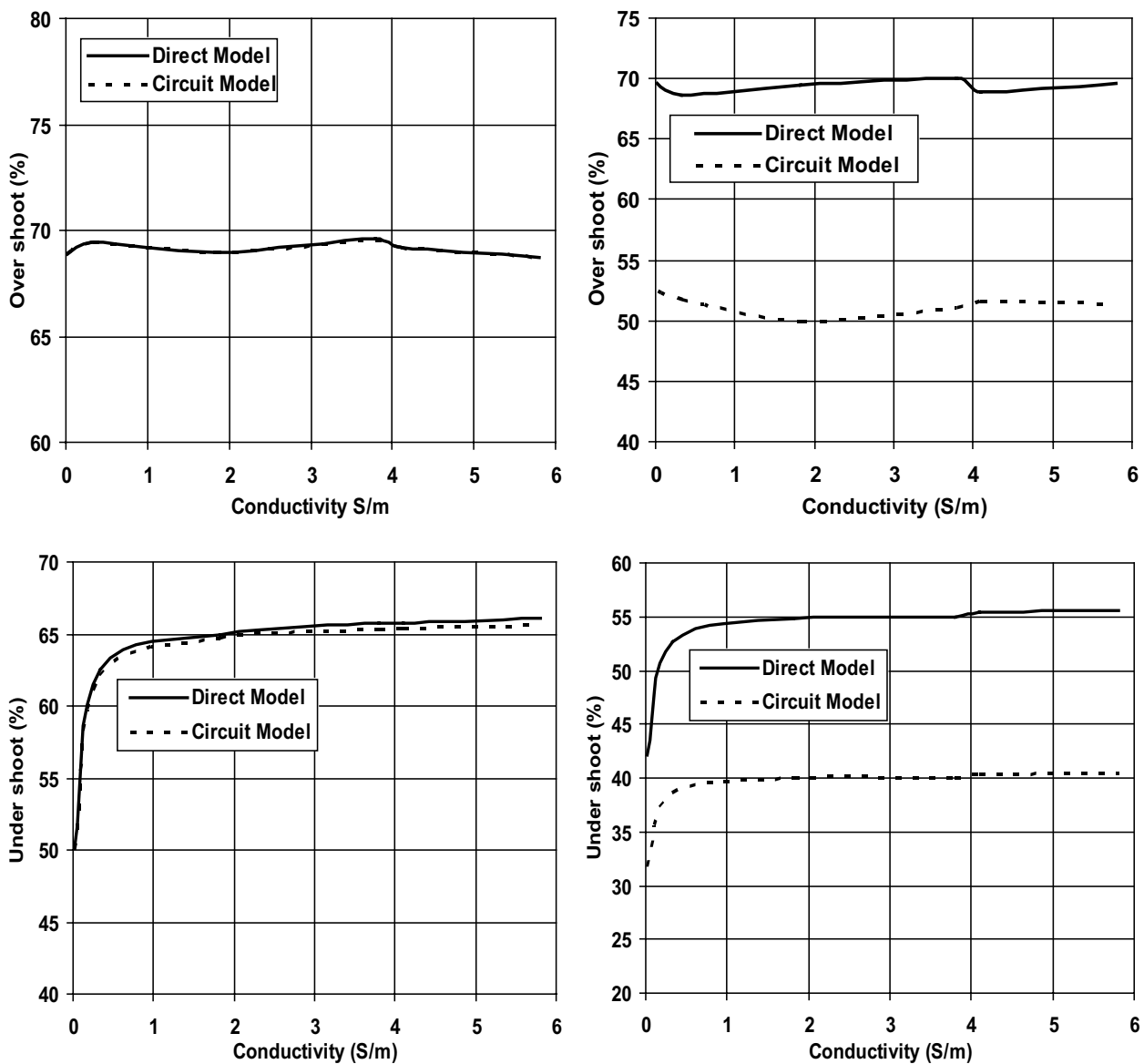

Table 6 Major advancements of the proposed work with the references [53-56]

\begin{tabular}{|c|c|c|c|c|}
\hline Signal frequency & Interconnect materials & Description & Technology & References \\
\hline $50 \mathrm{GHz}$ & Aerosol-jet silver & Optical interconnects & CMOS & {$[53]$} \\
\hline $10,45 \mathrm{GHz}$ etc. & Gold, poly-Si, SOI etc. & Optical + plasmonic interconnects & $\begin{array}{l}\text { CMOS, BiCMOS, } \\
\text { FPGA etc. }\end{array}$ & {$[54]$} \\
\hline $2.5 \mathrm{GHz}$ & Copper & Hybrid (wireless + electrical interconnects & CMOS & {$[55]$} \\
\hline $0.5 \mathrm{THz}$ & Multimode polymer & Optical interconnects & CMOS & {$[56]$} \\
\hline 10.0 THz simulated & $\begin{array}{l}\text { Copper, gold, aluminum, tungsten, } \\
\text { tungsten-silicide and poly-Si }\end{array}$ & Electrical interconnects & CMOS & {$[P]$} \\
\hline
\end{tabular}

P represents proposed work

to visualize the effect of propagation made by the various conducting materials which are widely used in CMOS technology and microwave integrated circuits as shown in Table 6. All parameters of transient pulse have been controlled by using integrated/circuit models and it has been verified with simulation results. The analyzed results could be useful in designing both on board and on-chip interconnects. All propagation effects are of importance in the performance analysis of designing integrated circuits interconnects in modern technologies.

\section{Compliance with ethical standards}

Conflict of interest The authors declare that they have no conflict of interest.

\section{References}

1. Zhu H, Shi R, Chen H, Cheng CK, Deutsch A, Katopis G (2006) Distortion minimization for packaging level interconnects. IEEE electrical performance of electronic packaging in Scottsdale. AZ, USA, pp 175-178 
2. Zhang L, Song JM (2006) Transient signal distortion in siliconbased interconnects over thin-film metal ground layers. IEEE electrical performance of electronic packaging in Scottsdale, AZ, USA, pp 145-148

3. Svensson C, Dermer GE (2001) Time domain modeling of lossy interconnects. IEEE Adv Packag 24(2):191-196

4. Djordjevi AR, Bilji RM, Smiljani VDL, Sarkar TK (2001) Wideband frequency domain characterization of FR-4 and time domain causality. IEEE Electromagn Compat 43(4):662-667

5. Wang P, Pei G, Kan ECC (2004) Pulsed wave interconnect. IEEE Very Scale Integr Syst 12(5):453-463

6. Deutesch A (2010) Application of the short-pulse propagation technique for broadband characterization of PCB and other interconnect technologies. IEEE Electromagn Compat 52(2):266-287

7. Awasthi YK, Singh H, Sharma M, Kumari S, Verma AK (2017) CADbased circuit model of microstrip line for $\mathrm{THz}$ interconnects technology. IET J Eng 9:512-526

8. Zheng GW, Chen KS, Peng ST (1990) Effects of substrate anisotropy on the dispersion of transient signals in microstrip lines. IEEE MTT-S Int Microw Symp Digest 2:657-660

9. Pramanick P, Bhartia P (1992) CAD models for microstrip on iso/ anisotropic substrates and their application to transient analysis. Int J Microw Millim-Wave Comput-Aid Eng 2:34-39

10. Verma AK, Awasthi YK, Singh H (2009) High-speed transient signals on anisotropic microstrip line with finite strip thickness. In: ISMOT, New Delhi India, pp 16-19

11. Awasthi YK, Verma AK (2008) Pulse propagation on Microstrip transmission-line Using an anisotropic substrate. In: IEEE recent advances in microwave theory and applications, India, pp 75-753

12. Yin WY, Guo B, Dong XT, Gan YB (2003) Diverse anisotropic effects in the multi-layer superstrate-substrates on the pulse propagation in shielded microstrip lines. IEE Proc Microw Antennas Propag 150(5):391-393

13. Chen KS, Zheng GW, Peng ST (1988) Dispersion characteristics of transient signals in microstrip step discontinuity. In: IEEE MTT-S international microwave symposium digest, New York, USA, pp 1775-1787

14. Hasnain G, Dienes A, Whinnery JR (1986) Dispersion of picosecond pulses in coplanar transmission lines. IEEE Trans Microw Theory Tech 34(6):738-741

15. Roskos H (1991) Propagation of picosecond electrical pulses on a silicon-based microstrip line with buried cobalt Silicide ground plane. Appl Phys Lett 58(23):2604-2606

16. Cam Nguyen (1998) Distortion of pulse on a terminated microstrip line of finite length. IEEE Int Symp Antennas Propag Soc 4:1850-1853

17. Hasegawa $\mathrm{H}$, Seki $\mathrm{S}$ (1984) On-chip pulse transmission in very high-speed LSI/VLSI. IEEE Microw Millim-Wave Monolith Circuits 84:29-33

18. Voranantakul S, Prince JL (1992) Trade-off design for high-speed pulse propagation in microstrip lines. Microw Opt Technol Lett 5(7):306-309

19. Whitaker JF, Norris TB, Mourou G, Hsiang TY (1987) Pulse dispersion and shaping in microstrip lines. IEEE Trans Microw Theory Tech 35(1):41-47

20. Whitaker JF, Sobolewski R, Dykaar DR, Hsiang TY, Mourou GA (1988) Propagation model of ultrafast signals on superconducting dispersive stripline. IEEE Trans Microw Theory Tech 36(2):277-284

21. Hsiang TY, Whitaker JF, Sobolewski R, Dykaar DR, Mourou GA (1987) Propagation characteristics of picosecond electrical transients on coplanar striplines. Appl Phys Lett 51(19):1551-1553

22. Zhang X, Fang JY, Mei KK (1988) Calculations of the dispersive characteristics of microstrips by the time-domain finite difference method. IEEE Trans Microw Theory Tech 36(2):263-267

23. Bernal J, Mesa F, Jackson DR, Langston WL, Williams JT (2010) High-frequency pulse distortion on a lossy microstrip line with a top cover. IEEE Trans Microw Theory Tech 58(7):1774-1785

24. Lee $\mathrm{CH}$ (1990) Picosecond optics and microwave technology. IEEE Trans Microw Theory Tech 35(5):596-607

25. Sali S (1991) Propagation of picosecond pulses in superconducting microstrip interconnections on integrated circuits. Int J Numer Model 4(3):203-223

26. Assadourian $F$ (1963) Characteristics of microstrip signals. In: Sucher M, Fox J (eds) Ch. XIX handbook of microwave measurement, vol III. Polytechnic Press of Polytechnic Institute, New York

27. Elliot RS (1957) Pulse waveform degradation due to dispersion in waveguide. IRE Trans Microw Theory Tech 5(10):254-257

28. Li KK, Arjavalingam G, Dienes A, Whinnery JR (1982) Propagation of Pico-second pulses on microwave striplines. IEEE Trans Microw Theory Tech 30(8):1270-1273

29. Kuo FF (1966) Network analysis \& synthesis, 2nd edn. Wiley, New York

30. Veghte RL, Balanis CA (1986) Dispersion of transient signals in microstrip transmission lines. IEEE Trans Microw Theory Tech 34(12):1427-1436

31. Leung T, Balanis CA (1988) Attenuation distortion of transient signals in microstrip. IEEE Trans Microw Theory Tech 36(4):765-769

32. Leung T, Balanis CA (1988) Pulse dispersion distortion in open and shielded microstrips using the spectral-domain method. IEEE Trans Microw Theory Tech 36(7):1223-1226

33. Gilb JP, Balanis CA (1989) Pulse distortion on multilayer coupled microstrip lines. IEEE Trans Microw Theory Tech 37(10):1620-1628

34. Gilb JP, Balanis CA (1990) Transient analysis of distortion and coupling in lossy coupled microstrips. IEEE Trans Microw Theory Tech 38(12):1894-1899

35. Gilb JP, Balanis CA (1991) Asymmetric multi-conductor low coupling structures for high-speed, high-density digital interconnects. IEEE Trans Microw Theory Tech 39(12):2100-2106

36. Pramanick P, Mansour RR (1991) Dispersion characteristics of square pulse with finite rise time in single, tapered, and coupled microstrip lines. IEEE Trans Microw Theory Tech 39(12):2117-2122

37. Qian Y, Yamashita E (1993) Characterization of picosecond pulse crosstalk between coupled microstrip lines with arbitrary conductor width. IEEE Trans Microw Theory Tech 41(6):1011-1016

38. Qian Y, Yamashita E (1993) Low-distortion and low-crosstalk characteristics of picosecond pulses in a dual-plane coupled microstrip lines structure. IEEE Microw Guided Wave Lett 3(8):273-275

39. Yin WY, Guo B, Dong XT, Gan YB (2003) Lossy effects on the transient propagation in LTCC coplanar waveguides (CPWS). Microw Opt Tech Lett 39(2):94-97

40. Malisuwan S, Ungvichian V (1999) Rise time effects on crosstalk in high-speed microstrip transmission lines. In: Proceedings 1999 Asia-Pacific microwave conference, vol 1, Singapore, pp 202-205

41. Kang K, Li LW, Yin WY (2004) Distortion of a square pulse wave with finite rise time in edge-coupled microstrip lines on LTCC substrate. Microw Opt Technol Lett 42(1):8-13

42. Yen YP, Kobayashi M (1998) Discussion on spikes and plateaus in pulse distortion shape along exponential microstrip taper. IEEE Trans Microw Theory Tech 46(7):1013-1015

43. Kobayashi M, Nemoto Y (1994) Analysis of pulse dispersion distortion along exponential and tchebycheff microstrip tapers. IEEE Trans Microw Theory Tech 42(5):834-839 
44. Verma AK, Kumar R, Sadr GH (1993) Pulse distortion on multilayer microstrip line. In: IEEE MTT-S, international microwave symposium digest, $\mathrm{pp} 861-864$

45. Verma AK, Kumar R (1998) Distortion in Gaussian pulse on microstrip-like transmission lines. Microw Opt Technol Lett 17(4):253-255

46. Verma AK, Kumar R (1993) Control of distortion in high-speed pulse propagation on microstrip line. In: 4th international symposium on recent advances in microwave technology, New Delhi, India, pp 543-546

47. Goossen KW, Hammond RB (1989) Modeling of picosecond pulse propagation in microstrip interconnections on integrated circuits. IEEE Trans Microw Theory Tech 37(3):469-478

48. Zheng J, Hahm YC, Tripathi VK, Weisshaar A (2000) CAD-oriented equivalent- circuit modeling of on-chip interconnects on lossy silicon substrate. IEEE Trans Microw Theory Tech 48(9):1443-1451

49. Ghione G, Maio I, Vecchi G (1989) Modeling of multi-conductor buses and analysis of crosstalk, propagation delay, and pulse distortion in high-speed GaAs logic circuits. IEEE Trans Microw Theory Tech 37(3):445-456

50. Wang $L$ (1998) Modeling of high-speed metal-insulator-semiconductor interconnections: the effect of ILD on slow-waveattenuation. http://inp.cie.rpi.edu/research/mcdonald/frisc/theses/LWang Thesis/LWangThesis.html, pp. 1-56. Accessed 23 Apr 1998
51. Hasegawa H, Seki S (1984) Analysis of interconnection delay on very high-speed LSI/VLSI chips using an MIS microstrip line model. IEEE Trans Electron Devices ED 31:347-352

52. Deutsch A (1990) High-speed signal propagation on lossy transmission lines. IBM J Res Dev 34(4):601-615

53. Ahmed E, Hannes R, Joris L, Peter O, Guy T, Jeroen M (2018) Aerosol-jet printed interconnects for $60-\mathrm{Gb} / \mathrm{S}$ CMOS driver and microring modulator transmitter assembly. IEEE Photonics Technol Lett 30(22):1944-1947

54. Christos AT, Eythimios NL, Niels N, Laurent S, Bert JO, Ronny $\mathrm{H}$, Dirk P, Frank E, Juerg L, loannis T (2018) Survey of photonic and plasmonic interconnect technologies for intra-datacenter and high-performance computing communications. IEEE Commun Surv Tutor 20(4):2758-2783

55. Ding Q, Mak T (2019) Hybrid interconnect network for on-chip low-power clock distribution. Electron Lett 55(5):244-246

56. Nikolaos B, Jonathan JDM, Enyuan X, Erdan G, Martin DD, Richard VP, Ian HW (2019) Ultra-low cost high-density two-dimensional visible-light optical interconnects. J Lightwave Technol 37(13):3305-3314

Publisher's Note Springer Nature remains neutral with regard to jurisdictional claims in published maps and institutional affiliations. 